\title{
A Review of the Applications of ASCAT Soil Moisture Products
}

\author{
Luca Brocca, Wade T. Crow, Luca Ciabatta, Christian Massari, Patricia de Rosnay, Markus Enenkel, Sebastian Hahn, \\ Giriraj Amarnath, Stefania Camici, Angelica Tarpanelli, and Wolfgang Wagner, Senior Member, IEEE
}

\begin{abstract}
Remote sensing of soil moisture has reached a level of good maturity and accuracy for which the retrieved products are ready to use in real-world applications. Due to the importance of soil moisture in the partitioning of the water and energy fluxes between the land surface and the atmosphere, a wide range of applications can benefit from the availability of satellite soil moisture products. Specifically, the Advanced SCATterometer (ASCAT) on board the series of Meteorological Operational (Metop) satellites is providing a near real time (and long-term, 9+ years starting from January 2007) soil moisture product, with a nearly daily (sub-daily after the launch of Metop-B) revisit time and a spatial sampling of 12.5 and $25 \mathrm{~km}$. This study first performs a review of the climatic, meteorological, and hydrological studies that use satellite soil moisture products for a better understanding of the water and energy cycle. Specifically, applications that consider satellite soil moisture product for improving their predictions are analyzed and discussed. Moreover, four real examples are shown in which ASCAT soil moisture observations have been successfully applied toward: 1) numerical weather prediction, 2) rainfall estimation, 3) flood forecasting, and 4) drought monitoring and prediction. Finally, the strengths and limitations of ASCAT soil moisture products and the way forward for fully exploiting these data in real-world applications are discussed.
\end{abstract}

Index Terms-Hydrology, radar, rain, remote sensing, weather forecasting.

Manuscript received June 28, 2016; revised November 28, 2016; accepted January 5, 2017. (Corresponding author: Luca Brocca.)

L. Brocca is with the Research Institute for Geo-Hydrological Protection, National Research Council, Perugia 06128, Italy (e-mail: luca.brocca@irpi.cnr.it).

W. T. Crow is with USDA-ARS, Hydrology and Remote Sensing Laboratory, West Beltsville, MD 20705-2350 USA (e-mail: wade.crow@ars.usda.gov).

L. Ciabatta is with Research Institute for Geo-Hydrological Protection, National Research Council, Perugia 06128, Italy, and also with the Department of Civil and Environmental Engineering, University of Perugia, Perugia 06123, Italy (e-mail:1.ciabatta@irpi.cnr.it).

C. Massari, S. Camici, and A. Tarpanelli are with Research Institute for Geo-Hydrological Protection, National Research Council, Perugia 06128, Italy (e-mail: c.massari@irpi.cnr.it; s.camici@irpi.cnr.it; angelica.tarpanelli@ irpi.cnr.it).

P. de Rosnay is with European Centre for Medium-Range Weather Forecasts, Reading RG2 9AX, U.K. (e-mail: Patricia.Rosnay@ecmwf.int).

M. Enenkel is with International Research Institute, Columbia University, New York, NY 10027 USA (e-mail: menenkel@iri.columbia.edu).

S. Hahn is with the Department of Geodesy and Geoinformation, Vienna University of Technology, Vienna 1040, Austria (e-mail: sebastian.hahn@ geo.tuwien.ac.at).

G. Amarnath is with International Water Management Institute, Colombo 10120, Sri Lanka (e-mail: A.Giriraj@cgiar.org).

W. Wagner is with the Department of Geodesy and Geoinformation, Vienna University of Technology, Vienna 1040, Austria (e-mail: wolfgang.wagner@ geo.tuwien.ac.at)

Color versions of one or more of the figures in this paper are available online at http://ieeexplore.ieee.org.

Digital Object Identifier 10.1109/JSTARS.2017.2651140

\section{NOMENCLATURE}

AMSR2 Advanced microwave scanning radiometer 2.

AMSR-E Advanced microwave scanning radiometer for EOS (earth observing system).

ASAR Advanced SAR.

ASCAT Advanced scatterometer.

CCI Climate change initiative.

CCI SM Climate change initiative soil moisture product.

ECMWF European Centre for Medium-Range Weather

Forecasts.

ECV Essential climate variables.

EnKF Ensemble Kalman filter.

EnKS Ensemble Kalman smoother.

ERS European remote sensing.

ESA European Space Agency.

ESM Earth system model.

EUMETSAT European Organization for the Exploitation of Meteorological Satellites.

EUMETCast EUMETSAT's multicast distribution system.

GCOM-W Global Change Observation Mission for Water.

GCOS Global climate observing system.

GEO Group on earth observations.

GLEAM Global Land Evaporation Amsterdam Model.

GPCC Global Precipitation Climatology Centre.

GPM Global precipitation measurement.

GPS Global positioning system.

GRACE Gravity recovery and climate experiment.

H SAF Satellite application facility on support to operational hydrology and water management.

IMERG Integrated multi-satellite retrievals for GPM, global precipitation measurement.

IPCC Intergovernmental Panel on Climate Change.

Metop Meteorological operational satellites.

NASA National Aeronautics and Space Administration.

NDVI Normalized difference vegetation index.

NEP Net ecosystem productivity.

NOAA National Oceanic and Atmospheric Administration.

NRT Near real-time.

NWP Numerical weather prediction.

RC Rainfall correction.

SAR Synthetic aperture radar.

SMAP Soil moisture active and passive.

SMART Soil moisture analysis tools.

1939-1404 @ 2017 IEEE. Personal use is permitted, but republication/redistribution requires IEEE permission. See http://www.ieee.org/publications_standards/publications/rights/index.html for more information.

(c) 2017 IEEE. Personal use of this material is permitted. Permission from IEEE must be obtained for all other uses, in any current or future media, including reprinting/republishing this material for advertising or promotional purposes, creating new collective works, for resale or redistribution to servers or lists, or reuse of any copyrighted component of this work in other works. 


$\begin{array}{ll}\text { SMOPS } & \text { Soil Moisture Operational Product System. } \\ \text { SMOS } & \text { Soil moisture and ocean salinity. } \\ \text { SSM } & \text { Surface soil moisture. } \\ \text { SWI } & \text { Soil water index. } \\ \text { SWVI } & \text { Soil wetness variation index. } \\ \text { TMI } & \text { TRMM microwave imager. } \\ \text { TMPA } & \text { TRMM multi-satellite precipitation analysis. } \\ \text { TRMM } & \text { Tropical rainfall measuring mission. } \\ \text { UNFCCC } & \text { United Nations Framework Convention on cli- } \\ & \text { mate change. } \\ \text { UTC } & \text { Universal coordinated time. } \\ \text { WGHM } & \text { WaterGAP Global Hydrology Model. }\end{array}$

\section{INTRODUCTION}

$\mathbf{S}$ OIL moisture plays a fundamental role in the hydrological cycle [158]. Indeed, the partitioning of water and energy fluxes between the land surface and the atmosphere is strongly dependent on the amount of water stored in the soil, i.e., soil moisture. On this basis, it is evident that the use of advanced technologies for improving the monitoring of soil moisture on a global scale will have large societal benefits (e.g., [124]). Currently, three different approaches are used for the monitoring of soil moisture from the point to the global scales: in situ observations, hydrological or land surface models, and remote sensing.

The monitoring of soil moisture over large areas through in situ observations is highly challenging (e.g., [130], [181]), but recent technologies are trying to fill the gap. For example, cosmic ray, global positioning system (GPS), distributed temperature sensing (DTS) and geophysical measurements (e.g., electrical resistivity, electromagnetic induction) ([150], [161], Larson et al. (2013), [33], [73]) are providing the opportunity to extend in space ground-based soil moisture measurement techniques (time and frequency domain reflectometry, gravimetric method, neutron probes) which are characterized by high accuracy but a very limited spatial representativeness (e.g., [61]). It should be underlined here that the spatial variability of soil moisture is characterized by the so-called "temporal stability" concept, i.e., the persistence in time of stable soil moisture spatial patterns [176]. Temporal stability can mitigate the spatial discrepancies between point measurements and the scale needed in the applications as it was shown that the temporal soil moisture evolution from point data might be considered representative of larger areas, e.g., $>100-200 \mathrm{~km}^{2}$ [29], [180], and vice versa large scale measurements are well correlated with point information (e.g., [24], [62], [134]) and useful for local scale $\left(<50 \mathrm{~km}^{2}\right)$ applications (e.g., [117]). Notwithstanding temporal stability, it is evident that the development of techniques providing measurements at $0.1-1 \mathrm{~km}$ scale would be vital [20]. However, the new techniques mentioned above (GPS, cosmic ray, geophysical) are still in their infancy. As a result, their broader applications still requires further investigations. Additionally, an underrepresented but important issue of in situ sensors is related to their maintenance. Indeed, it is highly difficult to find long-term in situ soil moisture time series with good quality and consistency over time [61].
Hydrological and/or land surface models are able to provide soil moisture estimates at the desired temporal and spatial resolution (e.g., subhourly and 100 m, [17]). However, every model is affected by uncertainties due to input data (i.e., meteorological observations and ancillary information as soil type and land use), calibration and model structure (e.g., [149]). Moreover, the spatial resolution of modeled soil moisture data often does not match the density of input meteorological observations (i.e., rainfall). In other words, if the models are forced with low density raingauge observations (as it usually happens), the derived modeled soil moisture data should be treated as representative of the resolution at which key model forcings are measured (which is commonly much coarser than the model grid size). Another fundamental issue affecting the modeling of soil moisture is related to the calibration of the soil parameters [182]. For instance, the saturated hydraulic conductivity, affecting the vertical and lateral movement of the water in the soil, is characterized by large variability [125], [203] and it cannot be observed over large areas and at different depths as it would be required [83]. The same applies to other soil hydrological properties, e.g., porosity, pore size distribution. Additionally, many key hydrologic processes are extremely difficult to parameterize (e.g., irrigation, dam operation, snow melting, interception), especially in challenging regions (deserts, pluvial forests, high altitudes). Based on these, and others, limitation, it is evident that simulated soil moisture data from hydrological and/or land surface models should be taken with caution. Again, the availability of actual soil moisture observations over large areas will be highly beneficial for these models [52], [168].

Remote sensing provides the unique opportunity to estimate global scale surface $(2-7 \mathrm{~cm})$ soil moisture measurements over large areas with good spatial $(\sim 20 \mathrm{~km})$ and temporal ( daily) coverage. Currently, several satellite soil moisture products are available from microwave, optical, and thermal sensors. We underline that recent advances in thermal and optical remote sensing for soil moisture estimation have been made (e.g., [103], [141]), but the present review will focus only on active and passive microwave-based products, with a particular focus on the Advanced Scatterometer (ASCAT) soil moisture product, as they are most widely used and most advanced. At the time of writing (November 2016), four quasi-operational, i.e., available either in near real time (NRT) or few days after sensing, coarse resolution satellite surface soil moisture products are available: 1) the soil moisture active and passive (SMAP) mission (Lband radiometer) starting from April 2015 with $\sim 36$ km/2-day spatial/temporal resolution [67]; 2) the Advanced Microwave Scanning Radiometer 2 (AMSR2) onboard the Global Change Observation Mission for Water, GCOM-W, satellite (C- and Xband radiometers) starting from July 2012 with $\sim 25 \mathrm{~km} / 1$-day spatial/temporal resolution [93]; 3) the Soil Moisture and Ocean Salinity (SMOS) mission product (L-band radiometer) starting from January 2010 with $\sim 50 \mathrm{~km} / 2$-day spatial/temporal resolution [91]; and 4) ASCAT onboard Metop-A and Metop-B satellites (C-band scatterometer) starting from January 2007 with $\sim 25 \mathrm{~km} / 1$-day spatial/temporal resolution [193]. Additionally, the ESA (European Space Agency) Climate Change Initiative (CCI) soil moisture product (CCI SM, [107]) is based on the 
merging of multiple active and passive microwave sensors thus providing a nearly daily product from 1978 to 2014 (at the time of writing) that is updated every year. Recently, higher resolution $(\sim 1 \mathrm{~km})$ soil moisture products are becoming available based on the disaggregation of coarse resolution products [112], [138] and, in the near future, from Sentinel-1 satellites (e.g., [132]). Others satellite sensors are currently employed for soil moisture retrieval, e.g., the WindSat Polarimetric Radiometer, and FengYun-3, but the delivery of the corresponding soil moisture products is still in a preliminary stage.

The brief overview reported above clearly underlines the amount of satellite soil moisture datasets that are currently available, their temporal coverage and spatial resolutions. Several validation studies have already demonstrated the accuracy (e.g., agreement with ground references) and reliability (e.g., time consistency) of these products through comparisons with in situ observations and land surface/hydrological modeling (e.g., [8], [24], [62] to cite a few). By way of example, the Pearson correlations with in situ observations was found to be in the range $0.5-0.8$ (interquartile range) with median values around 0.6 [24], [62], [134]. Therefore, there are many applications that could benefit from the use of satellite soil moisture products thanks to their long-term record (e.g., 36 years for ESA CCI SM product) and availability in near real time. Note that the ASCAT soil moisture product has a latency of only $130 \mathrm{~min}$ after satellite pass through the Satellite Application Facility on support to Operational Hydrology and Water Management (H SAF) project of EUMETSAT (European Organization for the Exploitation of Meteorological Satellites).

In synthesis, satellite soil moisture products can be used for evaluating and testing the structure of hydrological and land surface modeling [108], [168], for initializing meteorological, climate, hydrological, and crop/vegetation forecasts ([98], [99], [57], [100]), and in a data assimilation framework to constrain and update modeling states/parameters [25], [40], [63], [116], [146]. Additionally, the data can be used for studying the landclimate interactions and feedbacks [158] for monitoring of natural hazards (i.e., flooding, drought, heatwave, wildfire) and a number of other processes such as carbon sequestration, dust emissions, vehicle mobility [124]. The benefits obtained in recent studies employing satellite soil moisture datasets (e.g., [168], [193]) should encourage us to carry out new investigations to foster their use in different communities (hydrology, geomorphology, agriculture, etc.).

The main purpose of this review paper is to first underline the number of applications that could significantly benefit from the use of satellite soil moisture products. Therefore, the paper aims at assessing the status of satellite soil moisture products from the end user perspective, i.e., by mainly considering their spatial/temporal resolution, their consistency over time, their long-term availability, and their capability in improving the applications. Specifically, we will focus on the ASCAT soil moisture product(s), provided for free by EUMETSAT, which currently is the only satellite soil moisture product available operationally in near real time. Moreover, it is the only soil moisture product based on a sensor with a commitment to operational continuity in case of sensor failure (differently from
SMOS and SMAP). Therefore, it is definitely the most suitable product for operational hydrologic, climatic, and meteorological applications.

The paper is organized as follows. In Section II, the ASCAT instrument, the soil moisture retrieval algorithm and the ASCAT-derived soil moisture products are described shortly. In Section III, a general overview of the applications using satellite soil moisture products, by considering both active and passive microwave sensors, is given. In Section IV, four successful applications employing ASCAT soil moisture (and passive microwave) datasets are reported. Finally, in Section V, we highlight the strengths and limitation of using satellite soil moisture products for improving applications and some suggestions for the full exploitation of the data in an operational context are given in Section VI.

\section{ASCAT Instrument, SoIL Moisture Algorithm AND PRODUCTS}

In this section, we describe the instrument design of ASCAT, the surface soil moisture retrieval algorithm developed by the Vienna University of Technology and the ASCAT soil moisture products.

\section{A. ASCAT on-Board Metop}

The Advanced Scatterometer (ASCAT) on-board the series of Metop (Meteorological Operational Platform) satellites is a real aperture radar system operating in C-band $(5.255 \mathrm{GHz})$ and measuring the Normalized Radar Cross Section (NRCS), also called backscattering coefficient. Three Metop satellites constitute the space segment of the EUMETSAT Polar System (EPS), each with a nominal lifetime in orbit of about 5 years. The first satellite (Metop-A) was launched in October 2006 and the second satellite (Metop-B) in September 2012. The third and last satellite (Metop-C) is expected to be launched in 2018 superseding Metop-A. At the moment, Metop-A and Metop-B are operational and flying in a sun-synchronous 29 day repeat cycle orbit with a separation of half an orbital period ( $\sim 51 \mathrm{~min})$. The satellites are crossing the equator at a Local Solar Time (LST) of 09:30 A.M. and P.M. in descending and ascending orbit direction, respectively [74].

The instrument design of ASCAT is based on the experience of the scatterometer flown on the ERS-1 and ERS-2 satellite mission, including further improvements like increased spatial resolution and coverage, better radiometric accuracy and stability, as well as external transponder for in-orbit calibration [71]. ASCAT has two sets of three fan-beam antenna mounted broadside each covering a $550 \mathrm{~km}$ swath separated by $\sim 700 \mathrm{~km}$. The individual antennas (fore, mid, and aft antenna) are oriented at $45^{\circ}, 90^{\circ}$, and $135^{\circ}$ with respect to the satellite ground track and the incidence angle range varies between $34^{\circ}$ and $65^{\circ}$ (fore and aft antennas) and $25^{\circ}-55^{\circ}$ (mid antenna). Based on a spatial averaging applied in the along- and across-track direction a backscatter triplet is generated per orbit grid node for each swath. An operational backscatter product (ASCA_SZO, 50-km spatial resolution, 25-km spatial sampling) and a research backscatter product (ASCA_SZR, 25-km spatial resolution, 
12.5-km spatial sampling) are the main outputs in the Metop ASCAT Level 1b processing chain (http://eoportal.eumetsat.int). Ongoing changes in the Level 1 processor configuration and backscatter calibration lead to inconsistencies in the product history. Therefore, Fundamental Climate Data Records (FCDR) are produced on demand, which are based on a uniform Level 1 processing configuration and calibration. In 2015, the first MetopA ASCAT FCDR has been generated by EUMETSAT covering the period January 2007 to March 2014 (http://www.eumetsat. int/website/home/News/DAT_2704008.html).

\section{B. Soil Moisture Retrieval Algorithm}

The ERS (European Remote Sensing) and ASCAT instruments were not designed as dedicated soil moisture sensors; however, their multiangle measurement capability together with a high temporal coverage ( $<1$ day) make them a suitable instrument monitoring coarse-scale soil moisture changes. The semiempirical change detection method developed by the Vienna University of Technology (TU Wien), or the so-called TU Wien surface soil moisture retrieval algorithm, takes advantage of these key features. In the beginning, the TU Wien algorithm was tested for specific study areas on scatterometer data from the ERS-1 and ERS-2 satellite missions [190] and a first global realization covering 1992-2000 was released in 2002 [154]. Despite changes and improvements in the instrument design of ASCAT, only minor modifications were needed in the soil moisture processing chain [14] leading to a first near real-time (NRT) soil moisture data service from Metop ASCAT implemented at EUMETSAT. This service is now part of the H SAF NRT soil moisture data streams as described in the next section.

The TU Wien surface soil moisture retrieval algorithm has been developed out of the need to circumvent the lack of adequate backscatter models and the core conception of the model has not changed ever since its formulation [190]. However, a subject of ongoing research was, and still is, a better estimation of model parameters and error propagation [128], elimination of azimuthal effects [13] and improved vegetation correction [185]. The shortcomings of available theoretical models and high-quality reference datasets are the major constraints testing the performance of algorithmic improvements.

The definition of the TU Wien surface soil moisture retrieval algorithm is motivated by physical models and empirical evidence. The main model assumptions can be summarized as follows:

1) a linear relationship between backscatter (expressed in $\mathrm{dB})$ and soil moisture,

2) an empirical description of the incidence angle dependency of backscatter,

3) vegetation effects cancel each other via the so-called "cross-over angles" and

4) surface roughness and land cover are temporally constant. The change detection algorithm is comparing backscatter measurements normalized at a common reference incidence angle to the historically lowest/highest observation in the backscatter time series, thereby, also accounting for dynamic vegetation effects. The retrieved soil moisture information are thus given in degree of saturation units ranging between a completely dry $(0 \%)$ and saturated soil surface $(100 \%)$ representing the thin remotely sensed soil surface layer $(0.5-2 \mathrm{~cm})$. A conversion to absolute soil moisture units (e.g., $\mathrm{m}^{3} \mathrm{~m}^{-3}$ ) is possible by using additional information on soil properties [193].

\section{ASCAT-Derived Soil Moisture Products}

Reflecting the different application areas and meeting the demands of a diverse user community, several distinct ASCAT soil moisture data production lines have been set up, delivering free and open soil moisture data to a growing number of scientific and operational users [193]. The first service providing ASCAT soil moisture products is EUMETSAT's H SAF. At the H SAF website (http://hsaf.meteoam.it) users can find product documentation, e.g., Product User Manual (PUM), Algorithm Theoretical Baseline Document (ATBD), and following a successful registration are allowed to access the following ASCAT soil moisture products:

1) 25- and 50-km surface soil moisture (SSM) data expressed in relative units (degree of saturation) representing the thin remotely sensed soil surface layer $(0.5-2 \mathrm{~cm})$. These data are available in near real time (NRT) as swath images at the native ASCAT orbital grid nodes (referred to as: H101 Metop-A ASCAT NRT SSM $12.5 \mathrm{~km}$ sampling, H102 Metop-A ASCAT NRT SSM 25 km sampling, H16 Metop-B ASCAT NRT SSM 12.5 km sampling, H104 Metop-B ASCAT NRT $25 \mathrm{~km}$ sampling) or data records in time series format resampled to a discrete global grid (Metop ASCAT SSM time series data records: H25, H108H112). While the NRT data service has been tailored to meet the strict data latency requirements (delivery of the data within $\sim 130$ min after sensing) of the NWP community and other operational data users working at regional to global scales, the data records addresses scientific and other nonoperational data users interested in analyzing soil moisture data time series [194].

2) $25-\mathrm{km}$ root-zone soil moisture data at four layers $(0-7$, 7-28, 28-100, 100-289 cm) are derived by assimilating the ASCAT NRT SSM data in the ECMWF Land Data Assimilation System [56]. This product, referred to as SM-DAS-2 or H14, is available at a 24-h time step, with a global daily coverage at 00:00 Universal Coordinated Time (UTC). This product serves users requiring gap-free root-zone soil moisture data sampled at regular spatialtemporal intervals.

3) 1-km surface soil moisture data expressed in relative units (degree of saturation) are derived by downscaling the ASCAT NRT SSM data with static downscaling parameters estimated from SAR data using the method described by [191]. This product, referred to as disaggregated H08 Metop ASCAT NRT SSM at $1 \mathrm{~km}$, is available only over the European continent only and was developed to meet the high demand for higher resolution soil moisture data. However, as already noted by [193], its added value 
compared to the ASCAT NRT SSM data product is modest. Therefore, discussions on how to redesign the H08 data service are currently underway.

Building upon the 25- and 50-km ASCAT surface soil moisture products provided by $\mathrm{H}$ SAF, several other operational data services are providing value-added soil moisture products. Specifically, in many applications the knowledge of root-zone soil moisture is needed. For that, Wagner et al. [190] proposed the soil water index (SWI) method that allows us to obtain rootzone soil moisture estimates from surface soil moisture observations. The method is based on an exponential filter and has the effect of smoothing and retarding the soil moisture time series, mimicking the diffusion process of the water into the deeper soil layers [5, 37]. Based on this approach, the Copernicus Global Land Service (http://land.copernicus.eu) offers ASCAT-based $0.1^{\circ} \mathrm{SWI}$ data that quantifies soil moisture conditions at various soil depths at daily and ten-day time steps (for the ten-daily product, the SWI data are averaged over the respective time periods). In terms of its product characteristics, the SWI is comparable to the SM-DAS-2 or H14 product (mentioned above), yet with the important distinction that the SWI is much closer to the original satellite measurements because it is obtained without the use of a complex land surface modeling scheme.

Furthermore, ASCAT surface soil moisture products are an important input to the multisatellite soil moisture data records produced by ESA's Climate Chance Initiative (http://cci.esa. int) and by the Copernicus Climate Change Service (http:// climate.copernicus.eu). These two services are dedicated to producing and updating soil moisture data records that shall be as long, complete, and consistent as possible [62], [109], [192]. Given the long-term and stable nature of the well-calibrated Cband backscatter measurements provided by the series of European scatterometers, these measurements constitute a backbone to any climate soil moisture data record.

All data products mentioned above contain uncertainty estimates and various quality flags along with the soil moisture data fields themselves. The uncertainty estimates are typically derived from error analysis which propagates the noise of the ASCAT backscatter measurements and known uncertainties of the model parameterizations through the processing chains [128]. In case when soil moisture retrieval errors cannot be modeled in this way, or when soil moisture retrieval is not possible due to physical reasons (snow cover, frozen soil conditions, open water surfaces, high topographic complexity, urban areas, etc.), masks derived from ancillary datasets are provided.

While the algorithms and processing chains used to produce the different ASCAT soil moisture products have improved significantly over the years [13], [14], [128], the core scientific algorithms as originally proposed by Wagner et al. [189] for the ERS $1 / 2$ scatterometers and improved for use on a global scale by Scipal et al. [154] have remained remarkably stable. One important reason for that has been our limited capability to quantify soil moisture retrieval errors in detail, which itself was due to lack of suitable reference data and shortcomings in the validation methods. Fortunately, this has changed significantly in recent years due to increasing use of advanced error characterization methods such as triple collocation [77], [156], [163], frequency-domain analysis techniques [165], or data assimilation increment analysis [46], and the increasing availability of global in situ data [60], high-quality global land surface models [12], and other satellite soil moisture datasets [54], [90]. Therefore, our understanding of the strength and weaknesses of the ASCAT data products has improved significantly in recent years as summarized in [193]. This has motivated new research addressing the vegetation parameterization in the soil moisture retrieval algorithm [185] and efforts to characterize, and subsequently minimize, the spurious effects of subsurface scattering in dry environments [79]. These efforts can be expected to lead both to an improved error characterization and further improvements to the soil moisture retrieval algorithms.

In parallel to the steady improvements of the ASCAT soil moisture services, also the soil moisture data derived from the historic ERS-1 and ERS-2 scatterometer measurements keep on being improved through recurrent reprocessing activities. The purpose of these reprocessing activities is to ensure that the ERS Scatterometer data are brought up to the latest standard of the ASCAT data in terms of the instrument calibration and the soil moisture retrieval algorithm [45]. The historic ERS scatterometer data together with the Metop ASCAT data records form the most consistent multidecadal global soil moisture data record, and hence represents an essential input into soil moisture data records. Last, but not least, it should be mentioned that studies with Ku-band scatterometers also suggest that these instruments can be used for soil moisture retrieval over bare to sparsely vegetated areas [31], [122].

\section{OVERVIEW of (Potential) ApPlications of CoARse Resolution Satellite Soil Moisture Products}

In recent years, a couple of papers already reviewed the main applications of satellite soil moisture products and we suggest these studies for a complete overview of the topic [158], [168], [193]. Recently, the SMAP mission initiated the "Early Adopter" program (http://smap.jpl.nasa.gov/science/earlyadopters/) which aims to provide specific support to end users in order to accelerate the use of SMAP products. A full list of Early Adopters, subdivided by application's type, can be found in [124] and [69]. It provides an excellent summary of users interested in exploiting satellite soil moisture products for their applications.

Here, we provide a brief summary with an attempt to highlight the more recent results and applications. Moreover, we will focus on the use of coarse resolution $(>10 \mathrm{~km})$ satellite soil moisture products thus excluding applications using high resolution data ( $\sim 100 \mathrm{~m}$, Synthetic Aperture Radars, SARs), e.g., precision agriculture, biodiversity monitoring, and nutrient transport. As outlined above, soil moisture commonly governs the interaction between land surface and the atmosphere is thus an important variable in meteorological, climatic, and land applications. In the sequel, we separate the main applications based on the domain (i.e., "meteorological and climatic" and "land" applications) and we include also new applications in which the potential of satellite soil moisture products is still to be assessed. 
The applications treated in Section IV will be briefly mentioned here as fully described later in the text.

\section{A. Meteorological and Climatic Applications}

Influencing the exchanges of water and energy between the soil and the lower atmosphere, soil moisture is an important variable for meteorological [57] and climate [158] applications. Indeed, global scale numerical weather prediction (NWP) centers as ECMWF (European Centre for Medium-Range Weather Forecasts) and Met Office have already included in their operational analysis the assimilation of the ASCAT soil moisture product. The importance of soil moisture and the use of satellite observations for NWP [35], [56], [58], [155] will be analyzed in depth in Section IV-A.

The maturity of satellite soil moisture products has motivated the Global Climate Observing System (GCOS) to include soil moisture among the Essential Climate Variables (ECVs) in 2010 to support the work of the United Nations Framework Convention on Climate Change (UNFCCC) and the Intergovernmental Panel on Climate Change (IPCC). Through the ESA CCI, a long-term satellite-based soil moisture product is being delivered based on the combination of multiple C-, X-, and L-band microwave sensors [62], [107]. Additionally, within the European Copernicus program, synergistic studies including high-resolution sensors (e.g., Sentinel-1) will be carried out. Starting from these activities, a number of climate services are expected to grow for accelerating the technological transition from research (and public) to commercial (and private) sector [127].

For climate applications, the interactions and feedbacks between soil moisture and climate variables and fluxes have been the object of several studies (e.g., [65], [110], [200], and see [158] for a detailed review). In particular, satellite soil moisture products were considered in the analysis of the coupling between soil moisture and evapotranspiration [95], [114], [118], [157], soil moisture and air temperature [82], [119], [120], and soil moisture and precipitation [78], [167], [174], [175]. For instance, Martens et al. [114] used the satellite soil moisture product from SMOS mission for improving evapotranspiration estimation. SMOS data are assimilated through a simplified nudging scheme into the process-based evaporation model named GLEAM (Global Land Evaporation Amsterdam Model). First results highlighted that the assimilation of SMOS observations is slightly beneficial for the estimation of soil moisture (increase in Pearson correlation of $\sim 4 \%$ when compared with in situ observations) and quite neutral for evapotranspiration estimation. Hirschi et al. [82] analyzed the relationship between surface and root-zone soil moisture, obtained from the ESA CCI SM product, with the number of hot days on a global scale highlighting the important role of soil measurement depth in the coupling between soil moisture and temperature. Specifically under dry conditions, the soil moisture-temperature coupling is underestimated when using surface soil moisture products (directly sensed by satellite sensors) and it is better represented if root-zone observations are considered. The soil moistureprecipitation coupling has been the subject of several studies based on in situ observations, satellite data and modeling. In these studies, satellite soil moisture products were used for extending in space the first studies based on in situ observations [65], and for performing an observation-based validation of the soil moisture-precipitation feedbacks of global climate models Taylor et al. (2011). Indeed, soil moisture impacts on precipitation have been strongly debated. A recent study by Guillod et al. [78] tried to reconcile the previous investigation by using remote-sensing data and a common analysis framework and obtained that spatial and temporal correlations with opposite signs coexist within the same region and dataset. Very recently, Tuttle and Salvucci [175] collected AMSR-E derived soil moisture products and ground-based precipitation observations for the contiguous United States over 10 years. The feedback between soil moisture and rainfall was found to be generally positive in the western United States but negative in the east and it can be explained based on the different climates in the two regions. Overall, several open issues in the coupling and feedbacks between different variables (soil moisture, evapotranspiration, temperature, precipitation) is present but satellite soil moisture products have opened new opportunities for the observational analyses of land-climate interactions [119].

Another important peculiarity of soil moisture is represented by the so called "soil moisture memory," i.e., the persistence of water stored in the soil that induces persistence in the climate system [158]. As the timescales of soil moisture memory span weeks to a couple of months [68], soil moisture anomalies are associated with evaporation anomalies that may lead to subsequent precipitation anomalies [99]. Therefore, several studies have addressed the potential of using soil moisture observations for the initialization of subseasonal and seasonal forecasts [94], [96], [100], [131], [177]. For instance, Bisselink et al. [18] performed different regional climate simulations over Europe by using AMSR-E soil moisture product as initial condition. In general, for two case studies in 2003 and 2005, the use of AMSR-E data resulted in a better performance for predicting temperature when compared with observations, with increase in average Pearson correlation from 0.60 to 0.73 in 2003. Schneider et al. [153] used ASCAT and Envisat ASAR (Advanced SAR) soil moisture products for reducing model bias and increasing the spatial resolution of ECMWF (European Centre for MediumRange Weather Forecasts) forecasts and results confirmed that the incorporation of the new information added skill to seasonal forecasts.

\section{B. Land Applications}

Several studies have clearly demonstrated the potential of soil moisture in land processes such as floods and drought. Rainfall estimation, flood forecasting, and drought monitoring/prediction will be treated in Section IV.B-IV.D. Indeed, in these applications, satellite soil moisture products have been used quite extensively (e.g., [21], [23], [28], [47], [66], [116], [133], [135], [142], [197]).

Among the water-related natural hazards, soil moisture observations are needed also for the study of slope instability processes such as landslides and soil erosion (e.g., [19], [75]). Differently from floods and droughts, only three studies by Ray 
et al. [143], [144], with AMSR-E, and Brocca et al. [26], with ASCAT, demonstrated that satellite soil moisture products can provide useful information for the detection and prediction of landslide events. Similarly, only Todisco et al. [171] recently suggested the use of satellite soil moisture observations from ASCAT for predicting event soil loss at a plot scale with quite successful results in central Italy. The spatial mismatch between the targeted areas, typically a hillslopes or a small catchment, and the spatial resolution of satellite soil moisture product is the main reason for the limited use of these products. However, these first studies highlighted that the integration of satellite soil moisture products with meteorological information (i.e., rainfall) adds skill to the prediction of landslide and erosion and it represents an important topic that needs further investigations.

Satellite soil moisture products are also used for monitoring extreme conditions, i.e., drought and wildfire in very dry conditions and flooding in very wet conditions, and more generally for disaster monitoring. On the one hand, Lacava et al. [104] demonstrated the capability of the Soil Wetness Variation Index (SWVI) obtained by the Advanced Microwave Sounding Unit (AMSU) to monitor flooding conditions in Hungary (April 2000). Indeed, SWVI maps are able to detect the location and the extension of the areas affected by flood. Temimi et al. [169] and Naeimi et al. [129] obtained similar results in Iowa (US) and Mekong by using AMSR-E and ASCAT soil moisture products, respectively. Therefore, satellite soil moisture products are useful predictors of extreme wet conditions that may lead to flash floods occurrence and flooding. On the other hand, wildfire occurrence is often associated with drought. Indeed, strong Pearson correlations (in the range 0.64-0.94) between live fuel moisture content, a key variable in fire risk assessment, and soil moisture observations was obtained by using in situ observations (e.g., [139]). Therefore, satellite soil moisture products can be employed also for improving large scale fire forecast. Some initial examples of this were carried out by [10] in Africa by using the ASCAT derived SWI and by Piles et al. [137] in eastern Spain by considering a downscaled SMOS product. These studies showed that the spatial and temporal variability of dry soil moisture conditions can be related to fire occurrence. Overall, the highlighted applications showed that globally available, homogenous, and continuously updated satellite soil moisture datasets are an important factor for the effective assessment and monitoring of risk related processes. After the identification of appropriate warning threshold for hazard assessment, and the integration with vulnerability and susceptibility factors, these datasets can be effectively employed to determine potential risk and societal impacts [193].

Soil moisture is the main factor limiting plant growth, particularly in arid, semi-arid, and temperate climates. By regulating crop growth, soil moisture is a valuable indicator for agricultural monitoring and crop yields forecast [168] and microwave-based satellite soil moisture products have been frequently used in these applications [21], [51], [86], [160], Muñoz et al. (2014), [38], [41], [199]. For instance, Champagne et al. [38] used SMOS soil moisture observations for monitoring agricultural conditions in Canada highlighting the capability of SMOS to identify periods of drought and excess water potentially leading to crop losses. Zribi et al. [204] developed a simplified approach for predicting next month NDVI (Normalized Difference Vegetation Index) based on current month NDVI and soil moisture obtained from the ERS (European Remote Sensing) scatterometer during rainy season in Tunisia (see also [80] for a similar global-scale study). Closely related to the agricultural application, monitoring of soil moisture from satellite sensors has large potential to improve food security, mainly in developing countries such as Africa, southern America, and southeastern Asia. For instance, one of the main targets of SMAP mission is to contribute to the predictions of the Famine Early Warning Systems Network (http://www.fews.net/), which is currently primarily based on weather forecasts [69]. Soil moisture plays an important role also in the carbon cycle, and specifically in controlling the terrestrial carbon uptake [41]. Verstraeten et al. [183] integrated SWI data derived from the ERS scatterometer into the ecosystem carbon balance model C-Fix to assess 10-daily Net Ecosystem Productivity (NEP) patterns of Europe obtaining a general improvement in model predictions when compared with ground observations of Net Ecosystem Productivity (average increase in Pearson correlation from 0.7 to 0.72 ).

Soil moisture is an important variable also for the spread of plant pathogens (e.g., fungal diseases), and vector-borne human and animal diseases [168], [193]. Typical examples are represented by malaria carried out by the mosquito [123] and the Bluetongue virus of cattle carried out by biting midges [136]. These diseases have always been a serious public health issue for people and their livestock in tropical and subtropical regions but, due to global warming, these problems were also observed in mid-latitudes. So far, satellite soil moisture products have not been used for epidemic risk assessment and meteorological observations are usually employed for determining spatial and temporal occurrence of incidence rates (e.g., [42]). We carried out some preliminary analysis (not shown for brevity) looking at the correlation between scatterometer-derived soil moisture products and malaria incidence rates in Africa. In Mpumalanga and Botswana regions, where malaria data are available, a substantial good agreement is obtained (Pearson correlation between 0.6 and 0.7 ); thus, revealing the potential of these observations for this important application.

Finally, other applications that will benefit from spatialtemporal remotely sensed soil moisture estimates are related to the quantification of greenhouse gas emissions, the mapping of dust emissions, the evaluation of ground mobility of military vehicles, but no studies have been published on these topics so, even using ground-based soil moisture information [69].

\section{REAL-WORLD APPliCATIONS With ASCAT SOIL MOISTURE PRODUCTS}

In the following paragraphs, four specific applications are considered: 1) numerical weather prediction, 2) rainfall estimation, 3) flood forecasting, and 4) drought monitoring and prediction. For each application, a very short rational is given first for the use of remotely sensed soil moisture. After that, specific case studies are described in which ASCAT soil moisture products have been successfully employed. 


\section{A. Numerical Weather Prediction}

Soil moisture is a crucial component of the continental branch of the hydrological cycle whose representation is nowadays fully integrated in numerical weather prediction (NWP) systems. In particular, soil moisture is a key variable for near surface weather forecasts [56], [58]. It constitutes a water reservoir which interacts with the atmosphere on a large range of spatial and time scales [95], [131]. Soil moisture accumulates in the root zone and it is released to the atmosphere through the soil evaporation and vegetation transpiration which results from soil-vegetationatmosphere interaction processes. It is largely influenced by atmospheric conditions and it also varies depending on local surface conditions, such as soil and vegetation types as well as on the orography. In global mean annual terms, more than $60 \%$ of precipitation over land results from land evapotranspiration which (in turn) results from soil moisture-plant-atmosphere interactions. Soil moisture has also a very large influence on air temperature and air relative humidity whose high quality forecast is a strategic objective for NWP. Therefore, representing accurate soil moisture conditions in NWP model is of crucial importance to ensure reliable forecasts of near surface weather variables [36], [56]-[58]. Soil moisture is particularly important for weather forecast in situations where there is a strong coupling between the surface and the atmosphere and in case of extreme weather conditions. Soil moisture controls the evaporative cooling at the surface, and in extreme hot conditions, low soil moisture availability causes a positive feedback to the atmosphere. In regions with convective precipitation, such as in Sahel, soil moisture influences the mesoscale circulation and convective rain is more likely over drier soil than over wet soils [167].

There have been several challenges in the past 30 years concerning the development of the soil moisture representation in weather forecasting systems. In fact it is relatively recent that weather forecasting systems account for the physical processes that occur at the surface. In the 1970s and 1980s, weather forecasting and climate models were mostly representing atmospheric dynamic and physics, and land surface processes were accounted for in a very simplistic way. It was only in the 1990s that the scientific community started to invest in developing physically based soil moisture and land surface processes representations in models for climate and weather forecast applications [11], [184]. This was made possible by increased computing capabilities. However, using observations to constrain soil moisture was still marginal and we needed to wait until the 2000 s to see research developments on the use of observations to improve the accuracy of soil moisture in weather forecast systems [111]. Advances in atmospheric data assimilation have provided inspiration for the land surface model developments but with simplified and adjusted methods that are pertinent to land surface specificities, such as high spatial variability of surface parameters due to heterogeneities and long-time scales involved in the land surface processes.

As discussed in previous sections, several satellite instruments provide soil moisture information from space, such as ASCAT and more recently SMOS and SMAP. These instruments open new possibilities for improving soil moisture for NWP applications. ASCAT is particularly relevant for operational NWP applications since the products are available on the dedicated EUMETCast (EUMETSAT's Multicast Distribution System) system and the operational continuity of ASCAT is ensured on the Metop and Metop-SG satellite series. ASCAT soil moisture data assimilation is currently operational in several NWP centers such as ECMWF, the UK Met Office, and the Korean Meteorological Agency. Operational monitoring constitutes an important step of the data assimilation for NWP applications. It typically includes first guess departure (observations-model) statistics in the observation space. Fig. 1 illustrates monitoring of ASCAT surface soil moisture products as it is done operationally at ECMWF. It shows global maps of mean first guess departure (ASCAT surface soil moisture minus ECMWF model top layer soil moisture), for August 2016, for both Metop-A and Metop-B ASCAT soil moisture products available on EUMETCast. These two products enter the ECMWF land surface data assimilation system for operational NWP. This analysis is useful for detecting regional problems (i.e., high values of first guess departures) in the satellite data or the ECMWF model. It also illustrates the consistency of the ASCAT-A and ASCAT-B innovation statistics in the ECMWF data assimilation system.

However, using these data in NWP models has proven to be both technically and scientifically challenging as it requires the accurate representation of spatial heterogeneities and a good consistency between the water reservoir and fluxes in different components of the Earth system models. Scipal et al. [155] showed that assimilating ERS surface soil moisture product using a simple nudging approach improves both soil moisture and near surface weather forecasts compared to the model without data assimilation. However, when compared to the operational system that was in place at the time of their study, which was using proxy air temperature information to analyze soil, they found that assimilating ERS surface soil moisture with a nudging scheme slightly degrades the performances of the near surface weather forecasts. In a more recent study, De Lannoy et al. [55] presented results of ASCAT soil moisture data assimilation in the ECMWF NWP system based on ASCAT implementation preoperational experiments. In the ECMWF NWP system, ASCAT soil moisture and screen level (near surface) air temperature and air humidity are combined in a simplified Extended Kalman Filter data assimilation system to analyze soil moisture. They showed that the two types of observations are very complementary to correct the model soil moisture states, providing soil moisture increments (corrections) in different regions and at different soil depth, whereas ASCAT increments are mostly confined to the top soil moisture layer, near surface observations of air temperature and humidity, which are more linked to evaporation processes, allow to correct soil moisture in the root zone. In turn, ASCAT data assimilation is not limited to conditions with strong soil-air coupling, and it is therefore most efficient to use in areas and/or periods with weak coupling. So, there is a good complementarity between ASCAT surface soil moisture and proxy observation of air temperature to analyze soil moisture. 


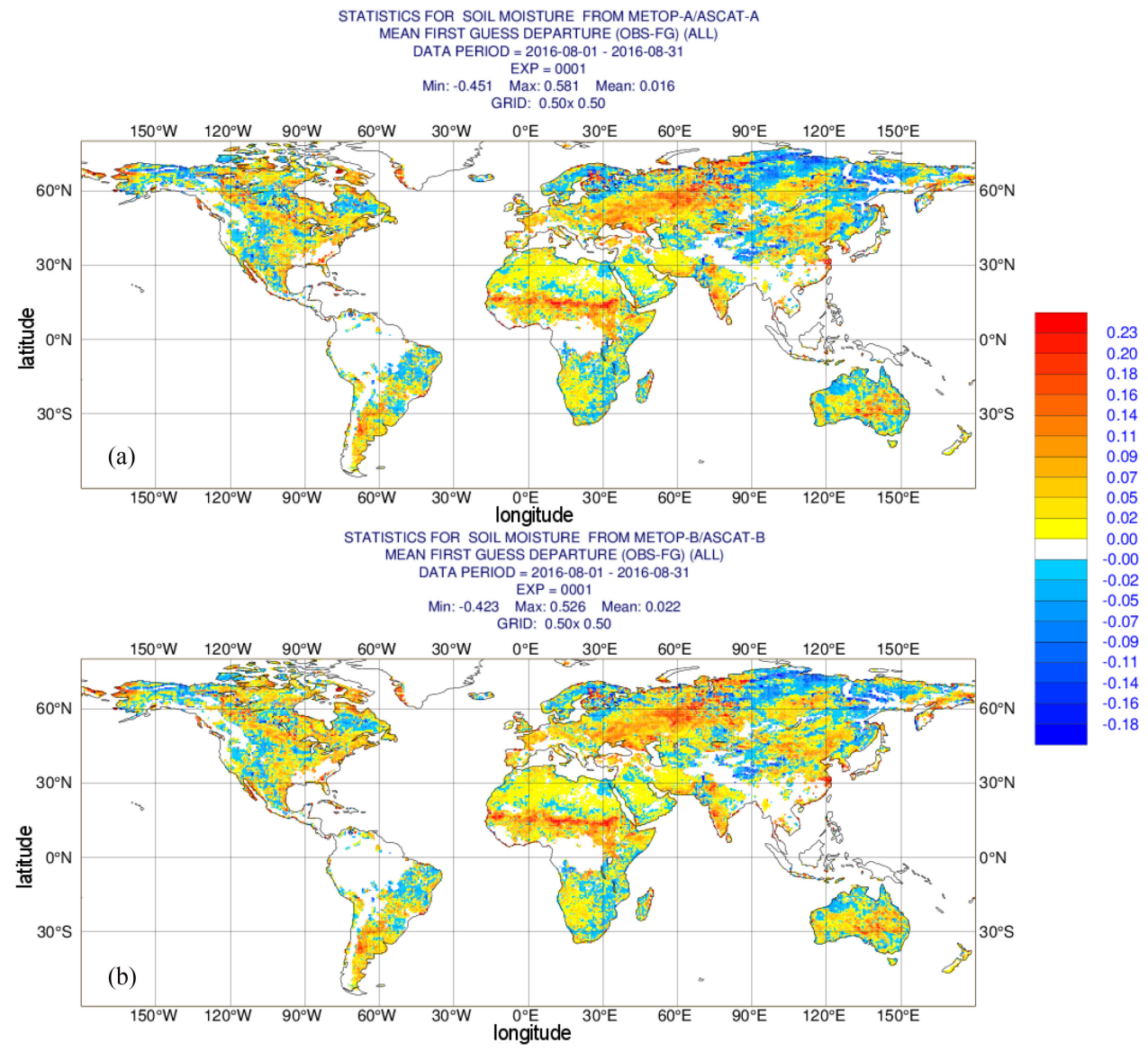

Fig. 1. Real-time monitoring of ASCAT soil moisture product through the ECMWF Integrated Forecasting System (http://www.ecmwf.int/en/forecasts/qualityour-forecasts/monitoring/soil-moisture-monitoring). Maps show the temporally averaged statistics of the first guess departure (observations-model) of the two soil moisture products currently available from Metop-A (a) and Metop-B (b) from the ECMWF soil moisture analysis in August 2016.

One of the major challenges in NWP system is to improve the consistency between the surface fluxes and water reservoirs which is currently achieved by combining different and complementary observations types to consistently constraint different components of the NWP systems. In the future, more missions related to land water storage and river discharge will provide further information that, when combined with ASCAT surface soil moisture products and in situ observations, will help to further improve NWP models.

\section{B. Rainfall Estimation}

Rainfall is by far the most important hydrometeorological variable for many climatic and hydrological applications [85]. The Group on Earth Observations (GEO) has identified precipitation as the first most important parameter, and soil moisture is the second, because it addressed so many user needs. However, in large parts of the world, ground-based observations of rainfall are sparse or absent and satellite-derived products are often the only source of information, mainly if real-time data are needed [102]. The retrieval of rainfall in the state-of-the-art products is based on a "top down" approach, i.e., rainfall is obtained through the inversion of the atmospheric signals scattered or emitted by hydrometeors [92]. These approaches provide an estimate of the instantaneous rainfall rate that needs to be aggregated for obtaining 3-hourly or daily estimates. However, because of its inherently intermittent nature (i.e., high temporal variability), rainfall is difficult to be determined reliably with a few instantaneous observations of rates [173], and this issue is particularly challenging for convective precipitation events. With the purpose of improving the accuracy of satellite rainfall products, some approaches using satellite soil moisture products have been recently developed [27], [48], [135], [198], following a "bottom up" approach. Among them, Brocca et al. [28] proposed a new method for directly estimating rainfall using soil moisture observations, called SM2RAIN. The method is based on the inversion of the soil water balance equation. It estimates the rainfall by using the change in time of the amount of water stored into the soil; thus, considering the "soil as a natural raingauge." SM2RAIN has been applied both on a local/regional [3], [27], [30], [31], [32] and a global scale [28], [101] with ground and satellite soil moisture products as input. Specifically, Brocca et al. [31] applied SM2RAIN to Ku-band backscattering measurements from RapidScat on board the International Space Station. Results in central Italy were found to be satisfactory with 1-day Pearson correlation higher than 0.6 in the comparison with ground rainfall observations. This study highlights the large potential of using the constellation of 


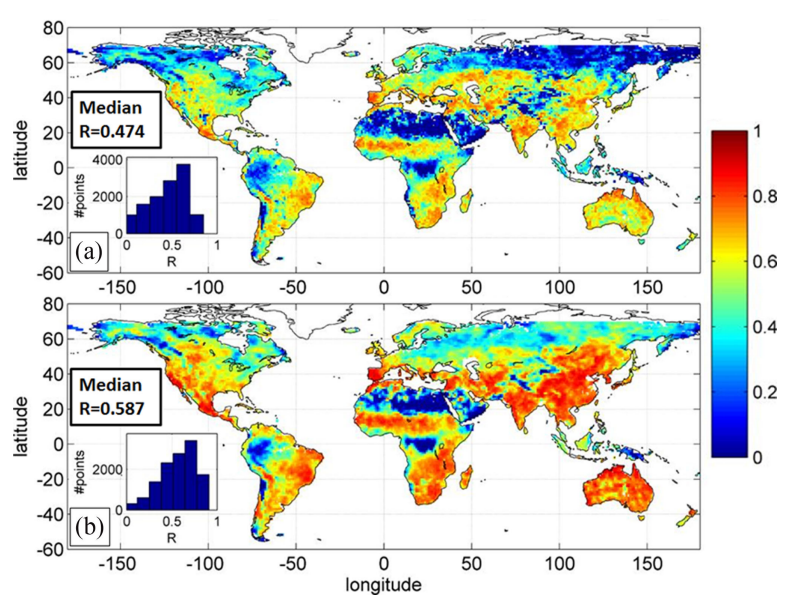

Fig. 2. Correlation maps between gauge-based rainfall observations (GPCC Full Data Daily Product) and two versions of SM2RAIN-ASCAT product: (a) product delivered by Brocca [28], and (b) new product (doi:10.13140/RG.2.1.4434.8563). Results are shown for five-day accumulated rainfall, $1^{\circ}$ spatial sampling, and in the period 2007-2012. The insets show the distribution of R-values (R: Pearson correlation coefficient). The bottom panel shows higher values everywhere highlighting the significantly improved performance of the new product.

scatterometers (C- and Ku-band) for providing an accurate rainfall product with high spatial-temporal resolution. On a global scale, Brocca et al. [28] delivered three rainfall products obtained by ASCAT, SMOS, and AMSR-E soil moisture products with $1^{\circ}$ and 1-day spatial-temporal sampling. Quite unexpectedly, the ASCAT-derived rainfall product was found to be the more accurate [28] with performances similar to the real-time version of TRMM multi-satellite precipitation analysis, TMPA, product (3B42RT). Koster et al. [101] applied SM2RAIN to SMAP soil moisture data obtaining Pearson correlation of $\sim 0.77$ in areas of high rain gauge density.

Very recently, the rainfall product obtained from ASCAT, called SM2RAIN-ASCAT, was updated and it is freely available at http://dx.doi.org/10.13140/RG.2.1.4434.8563. The product has a spatial sampling of $0.5^{\circ}$, and a temporal coverage from January 2007 to June 2015. Fig. 2 shows the comparison of the Pearson correlation maps obtained with the new ASCATderived product against the one delivered by Brocca et al. [28]. Maps show the correlation between satellite and ground-based data (Global Precipitation Climatology Centre, GPCC, Full Data Daily Product, [152]) for five-day accumulated rainfall, $1^{\circ}$ sampling (the new product was resampled), in the period 20072012. As it can be seen, the new product provides significantly higher performances with global scale median Pearson correlation increasing from 0.474 to 0.587 . This finding is attributed to the higher quality of the more recent ASCAT soil moisture product, to the enhancements in the SM2RAIN algorithm mainly addressing noise reduction, and to the improved calibration that is carried out on pixel-by-pixel basis and with a higher spatial sampling $\left(0.5^{\circ}\right.$ with respect to $\left.1^{\circ}\right)$. Moreover, we note that further improvements are expected if the more recent period were analyzed in which ASCAT sensor is available also onboard Metop-B satellite. A dedicated study by researchers of the National Research Council and of the Vienna University of

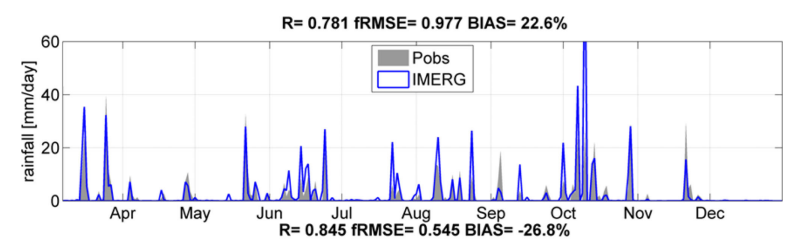

(a)

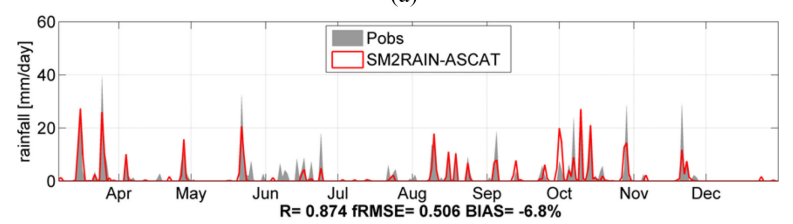

(b)

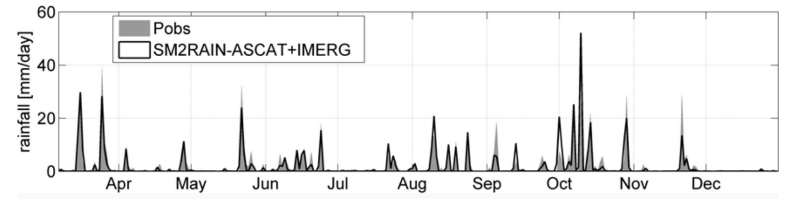

(c)

Fig. 3. Integration of SM2RAIN-ASCAT and IMERG (late run) rainfall products in central Italy (March-December 2015): time series of gauge-based daily rainfall (Pobs) and IMERG (a), SM2RAIN-ASCAT (b), and SM2RAINASCAT+IMERG (c) products (R: Pearson correlation coefficient; fRMSE: fractional RMSE, i.e., RMSE divided by the temporal standard deviation of observed rainfall). The integrated product (SM2RAIN-ASCAT+IMERG) provides the best performance scores both increasing the temporal correlation and reducing the BIAS.

Technology is underway to fully understand the capabilities, i.e., spatial-temporal resolution, accuracy, and coverage, of ASCAT for the retrieval of high-quality rainfall observations over land.

The integration of the "top down" and "bottom up" perspectives is also expected to provide a higher quality rainfall product that takes advantage of the benefits of both approaches. In fact, the two perspectives are highly independent and complementary: the "bottom up" products are able to estimate accurately the accumulated rainfall but fail during saturated wetness conditions; the "top down" products are able to estimate intense rainfall events, usually bringing to wet conditions, but fail in reproducing light rainfall events. First validation results in Italy have shown promising results [43] as the product integrating SM2RAIN-ASCAT either the real-time version of TMPA product (3B42RT) or the H SAF H05 product is found to outperform the parent products. Based on these results, in the third phase of H SAF project (2017-2022), a new precipitation product in near real-time that integrates SM2RAIN-ASCAT and H SAF precipitation products is foreseen. A recent update is shown in Fig. 3 in which SM2RAIN-ASCAT is integrated with the recently available late run version of IMERG (Integrated Multi-satellitE Retrievals for GPM, Global Precipitation Measurement) product for one location in central Italy. The daily rainfall time series for the three products are very well in agreement with observations (Pearson correlation $>0.78$ ) and the integrated product SM2RAIN-ASCAT+IMERG is providing the best performance with a Pearson correlation close to 0.9. It should be underlined here that the comparison is carried out at 1-day time scale and, hence, results are really outstanding as they are based on satellite-data only. 


\section{Flood Forecasting}

Floods are among the most dangerous and costly of all natural disasters causing extensive economic and social damages worldwide [196]. This issue is compounded by the recent intensification of the frequency and magnitude of extreme events (e.g., heavy precipitation, storms) likely due to climate change [34], [87]. In a recent study in the United States (US), Janssen et al. [88] observed an overall increasing trend in extreme precipitation events from 1901 to 2012, and model simulations show an underestimation of extreme events compared with observations [9]. Future projections of Earth System Models (ESMs) suggest further increases in extreme precipitation frequency in a high-emission scenario. This needs to be considered carefully, given the knowledge that the models tend to be on the low side of observations [81], and the increase of the vulnerability and exposure of assets [89]. The brief summary here reported highlights the pressing need for improved methods for the mitigation of the impact of flood risk on society (e.g., [70]).

Soil moisture is the key variable in the partitioning of rainfall in infiltration and runoff thus paying a fundamental role in flood forecasting [98]. Satellite surface soil moisture products can bring important benefits in the mitigation of flooding hazard both through an improved initialization of rainfall-runoff models [15], [22] and data assimilation techniques (e.g., [23], [25], [106], [117]). However, several issues should be addressed: 1) the spatial mismatch between coarse resolution satellite soil moisture products and the typical scale of hydrological studies $\left.\left(200-1000 \mathrm{~km}^{2}\right), 2\right)$ the shallow penetration depth of satellite data that contrasts the need of root-zone information in rainfallrunoff models, and 3) the development of rainfall-runoff models specifically targeted to the use or assimilation of satellite data (most of the models were not conceived with this target, e.g., by including a shallow soil layer close to the surface). In a data assimilation framework, additional open questions are present, e.g., the assessment of the error of observations and modeling, the selection of the data assimilation approach, the technique for rescaling observations to model states. Massari et al. [116] summarized the different issues in a framework of a cooking recipe in which the three ingredients are the hydrological model, the data assimilation technique, and the satellite soil moisture product(s); and the cooking techniques are the different options (sometimes quite subjective) to be selected to cook the ingredients. Obviously, the final results depend both on the ingredients and on the cooking (or the cook). These issues led to the publication of different studies in the scientific literature in which a number of conflicting conclusions can be found thus making difficult a general interpretation of the utility of data assimilation of satellite soil moisture products into rainfall-runoff modeling (e.g., [6], [39], [117]).

Notwithstanding the above points, mainly in the last 2-3 years, a number of studies demonstrated the benefit of assimilating satellite soil moisture products for hydrological simulations and flood modeling by performing more detailed studies. For instance, Wanders et al. [197] and Alvarez-Garreton et al. [7] obtained that the assimilation of multiple satellite soil moisture products (SMOS, ASCAT, and AMSR-E) improves the

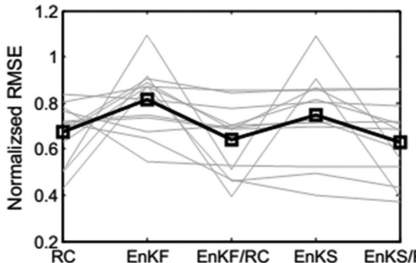

(a)

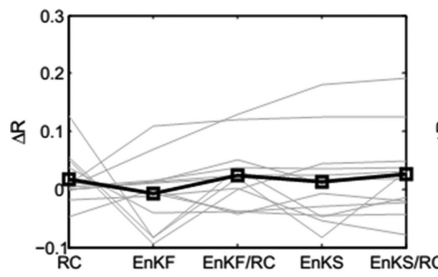

(c)

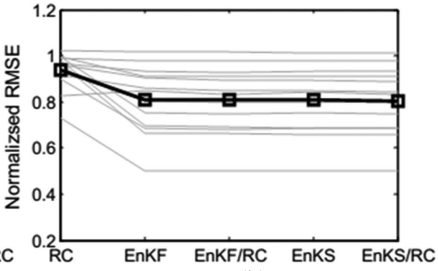

(b)

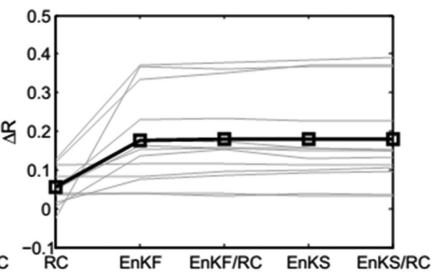

(d)
Fig. 4. Changes in: (a) raw stream flow RMSE (normalized the RMSE obtained prior to any soil moisture data assimilation), (b) normalized log flow RMSE, (c) raw flow correlation coefficient difference (relative to correlation obtain prior to any soil moisture assimilation), and (d) log flow correlation coefficient difference associated with a range of rainfall correction (RC) and state-updating (EnKF or EnKS) data assimilation approaches. Individual basins are shown as grey lines and bold lines with square-symbols are averages obtained across all basins. Overall, stream flow accuracy was maximized by simultaneous correction of both rainfall forcing (RC) and antecedent soil moisture states (EnKF or EnKS) using remotely-sensed soil moisture Adapted from [40].

hydrological simulation for one basin in Europe (Danube River) and in Australia (Warrego River). Massari et al. [116], following the previous studies by Brocca et al. [23], [25], assimilated the ASCAT surface soil moisture product for five basins in central Italy with different physiographic (topography, soil, land use, size) characteristics. Results showed that the assimilation improves flood simulation for 4 out 5 basins and that the soil type and the wetness conditions have a strong impact on the assimilation results. The Efficiency Index, that identifies the percentage improvement or deterioration due to the soil moisture assimilation, was found varying from $25 \%$ to $42 \%$ in the four basins.

The success of approaches for directly estimating rainfall via ASCAT surface soil moisture time series retrievals shown in the previous paragraph opens up the possibility that ASCAT can be used to simultaneously improve both prestorm antecedent soil moisture conditions and within-storm rainfall amounts for a hydrological forecasting system [49], [115]. Utilizing a combination of SMOS and ASCAT surface soil moisture products, Chen et al. [40] developed such an approach and applied it to improve stream flow estimates within a series of moderate-size basins within the central United States. Antecedent state correction was performed using both an Ensemble Kalman Filter (EnKF) and an Ensemble Kalman Smoother (EnKS). Simultaneous rainfall correction $(\mathrm{RC})$ was applied via the Soil Moisture Analysis Tools (SMART; [50]). Fig. 4 summarizes the impact of correction processes on the accuracy of outlet stream flow predictions. Overall, stream flow accuracy was maximized by simultaneous correction of both rainfall forcing (RC) and antecedent soil moisture states (EnKF or EnKS) using remotely sensed soil moisture. Therefore, ASCAT has demonstrated the ability to contribute to both prestorm (i.e. infiltration capacity) and within-storm (i.e. storm-scale accumulation) aspects of 
a hydrologic prediction system. Similarly, Ciabatta et al. [44] found that the correction of ground observed rainfall through SM2RAIN-ASCAT product provides significant improvement in flood modeling when compared to the use of rain gauge observations only in three out of four basins throughout the Italian territory (the average Nash-Sutcliffe efficiency increases from 0.65 to 0.75 in the validation period). Overall, these types of approaches are particularly valuable over regions of the world lacking high-quality operational rain gauge availability.

In summary, several papers concluded that there is a strong need for further studies focusing on soil moisture data assimilation for the purposes of improving streamflow prediction from rainfall-runoff models. The current availability of different satellite soil moisture products, also for long-term period, allows to really perform robust and reliable procedures for providing general guidelines or rules for a proper data assimilation everywhere. As mentioned above, the availability of the ASCAT soil moisture product in near real time (130 min after sensing) makes the product highly suitable for this kind of approach.

\section{Drought Monitoring and Prediction}

According to the Global Facility for Disaster Risk and Recovery [170], an annual average of 224 disasters that could be linked to hydrometeorological extreme events were recorded in the 1990s. In the 2000s, this number increased to 344 disasters annually. With regard to drought and extreme temperatures, there is a clear positive trend since the 1970s in the emergency events database (www.emdat.be). However, since there are many drought indicators, but no common definition of drought [16], [202], research studies have yielded contradicting results with respect to trends in drought frequency and severity. The studies of Sheffield et al. [159] and Dai [53], titled "Little change in global drought over the past 60 years" and "Increasing drought under global warming in observations and models" respectively are examples of this contradiction. Hence, even if the recorded trends might partly be attributed to improvements in documentation and if the increasing frequency is not as severe as expected, the number of drought events affecting vulnerable communities is high. Satellite-derived soil moisture can play a manifold role in drought management due to its importance in the global hydrologic cycle [172] and its added-value for the estimation of drought onset, severity, duration, and frequency. Consequently, user-focused tools that use satellite soil moisture for decision-making as an additional source of information are promising for all drought categories. In general, three drought categories, which usually do not appear simultaneously, can be distinguished: meteorological, agricultural, and hydrological drought. They all have in common that they follow a deficit in rainfall, which leads to a water shortage for a certain application (e.g., agriculture) and/or user group (e.g., farmers) [202]. Additionally, Van Loon et al. [179] highlighted that we need to rethink the concept of drought to include the human role in mitigating and enhancing drought.

With regard to meteorological drought, which is usually the precursor for the two other drought categories, the addedvalue of satellite-derived soil moisture lies for instance in the

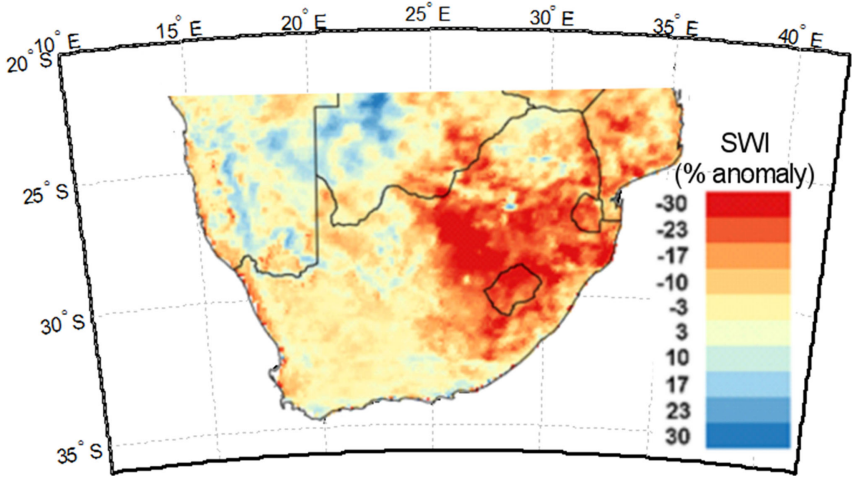

Fig. 5. ASCAT-derived Soil Water Index (SWI) monthly anomaly for November 2015 for South Africa, scaled between $-/+30 \%$ anomaly. The south-eastern regions of South Africa experienced a heat wave, resulting in the most severe drought event in 23 years, that matches well with the areas characterized by the lower values of SWI (in red).

validation of rainfall estimations. Inverting the water balance equation to estimate and validate precipitation amounts via satellite soil moisture observations [27], [28], [48] is a promising approach to capture critical rainfall deficits early in the season. This approach can particularly be useful in regions where the estimation of light precipitation events is problematic due to a general underestimation of accumulated rainfall [102].

Agricultural drought monitoring requires information about atmospheric deficits and the response of crops (e.g., via satellitederived vegetation indices) before and during the agricultural season. The rainy season is naturally characterized by an increased cloud cover, which is problematic, e.g., for sensors that operate in the infrared domain [187]. Since scatterometers used for soil moisture retrieval operate in the microwave domain their observations are not impeded by cloud cover [188]. Qiu et al. [140] highlight the importance of surface soil moisture for drought monitoring and root-zone soil moisture, as represented by the SWI [5], [189], for the estimation of the near-future vegetation condition. Fig. 5 illustrates SWI anomalies obtained from ASCAT soil moisture product over South Africa for November 2015. In 2015, the Eastern regions of South Africa experienced a heat wave, resulting in the most severe drought event in 23 years and the third driest season in 80 years ([147], [148]). The dark red colors in Fig. 5 match well with local observations and media reports. The El-Niño-related event resulted in reduced crop yields, animal production, and increases in maize prices. An example of drought index in India that used CCI SM product to better characterize the agriculture drought against variables only based on vegetation and rainfall is shown in Fig. 6. When qualitatively compared with ground-truth surveys, the representation of drought extent is found to be better predicted with the use of satellite soil moisture products, and a detailed intercomparison analysis is underway.

Hydrological drought is defined by the impact of precipitation shortages on surface and subsurface water supply [201]. Abelen et al. [2] related ASCAT surface soil moisture to total water storage (soil moisture, surface water, snow ice, and groundwater) variations detected via NASA's (National Aeronautics and Space Administration) satellite gravity mission Gravity 


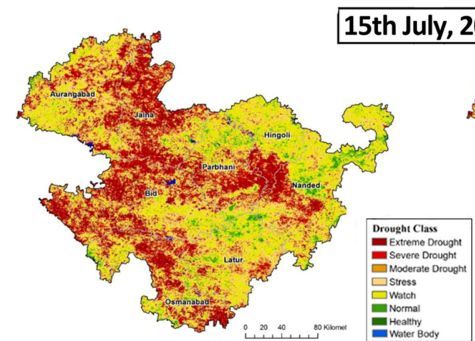

(a)

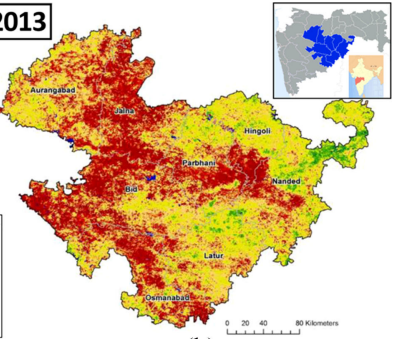

(b)
Fig. 6. Drought severity index for Marathwada region in Maharashtra, India, for 15 th July, 2013. The image on the left (a) highlights drought condition based on the IWMI Integrated Drought Severity Index (IDSI) including vegetation and rainfall data. The image on the right (b) uses CCI soil moisture data in addition to vegetation and rainfall and, qualitatively, is able to better reproduce the ground observed drought extent.

Recovery and Climate Experiment (GRACE). In particular, the GRACE observations corresponded well to daily ASCAT soil moisture observations in arid environments [1]. Also in case of the Argentinean La Plata basin, ASCAT surface soil moisture served as a good indicator for total hydrological extreme events. The observations from ASCAT corresponded well to water storage change (GRACE) (Pearson correlations up to 0.8 in the North of the La Plata basin) and changes in groundwater levels (Pearson correlations up to 0.7 in the North of the La Plata basin) modeled by the WaterGAP Global Hydrology Model (WGHM) [2].

Besides the direct use of remotely sensed surface soil moisture retrievals for drought monitoring and prediction, the data are increasingly being assimilated into continuous land surface models to enhance agricultural drought monitoring products [21]. Such assimilation requires statistical knowledge of errors afflicting both modeled and remote sensing-based soil moisture estimates. As the only long-term scatterometer-based soil moisture dataset in existence, ASCAT surface soil moisture retrievals play a unique role in providing this type of statistical error characterization. For example, Crow and Yilmaz [52] demonstrate how ASCAT soil moisture products can be combined with independent soil moisture datasets acquired from water balance modeling and passive microwave remote sensing to optimally parameterize a land data assimilation system tasked with characterizing soil moisture anomalies (via the integration of multiple satellite-based soil moisture and precipitation retrievals). This ability to parameterize errors extends to the calculation of lateral error-covariance information required to fully parameterize 2-D data assimilation systems [76]. Therefore, due to their unique independence with regards to all other available global soil moisture datasets, ASCAT surface soil moisture can be used to enhance the overall performance of a land data assimilation system, and consequently its capability to forecast drought conditions.

\section{Discussion On STRENGTHS AND Limitations of ASCAT SOIL MOISTURE PRODUCTS}

In the previous two sections, the impact of satellite soil moisture products for different applications is outlined with a particular emphasis on ASCAT-derived products. In order to provide current and future end-users (and scientists) interested in utilizing ASCAT soil moisture products a quick introduction, the strengths and limitations of ASCAT soil moisture products are discussed here. Whenever possible, the comparisons with the other soil moisture products obtained from C- and Lband microwave sensors currently available, i.e., SMAP, SMOS, AMSR-E, and AMSR2, will also be discussed.

The main strengths of the ASCAT soil moisture product can be summarized in the following points:

1) The ASCAT sensor is based on a well-established technology providing high radiometric accuracy, multipleviewing capabilities, and high signal-to-noise ratio [193]. Therefore, notwithstanding the nonoptimal wavelength range of ASCAT (C-band), the quality of the obtained soil moisture product is found to perform comparably with SMOS and AMSR-E on a global scale [8], [24]. For some applications (e.g., [28]), ASCAT soil moisture retrievals are found to outperform similar radiometer-based products from AMSR-E and SMOS. Additionally, the ASCAT soil moisture product is the only one that is currently assimilated operationally by ECMWF and UK Met Office for global scale weather forecasts.

2) The ASCAT soil moisture product has: 1) high temporal consistency, 2) is available for more than 9 years, and 3) is part of a long-term program currently scheduled until mid2040s. Such (past and future) continuity is tremendously important from the end-user perspective, especially for climate community. Anyhow, even nonclimate applications, addressing the monitoring or prediction of limited duration events (e.g., flood forecasting), require a long-term and consistent data record in order to test and evaluate the possibility to uptake new satellite-based products. For instance, most of the hydrological models currently used for flood prediction and forecasting have a structure not suitable for ingesting satellite soil moisture observations [25]. The selection of the more appropriate modeling structures for making them suitable for exploiting satellite information needs long-term data ( $>5$ years) in order to build consistent techniques. Currently, ASCAT is the only sensors with a long-term data record (since 2007) followed by SMOS which started in 2010.

3) The ASCAT soil moisture product is characterized by both good spatial-temporal sampling ( $\sim 25 \mathrm{~km}$ and 1-day) and wide spatial coverage. Both these characteristics are expected to improve in the near future with the launch of the new Metop-SG SCA sensors scheduled in 2020s [72]. The spatial-temporal resolution of ASCAT is the best available among the different soil moisture sensors currently in orbit and it is already appropriate for many applications (see above).

4) ASCAT datasets are available in near real-time (NRT) through the EUMETCast system (130 min after sensing). Obviously, low data latency is a strong prerequisite for all operational applications such as NWP and flood/landslide forecasting (e.g., [23], [197]). As described above, recent studies have demonstrated the capability of ASCAT 
soil moisture product for estimating rainfall and, also in this context, the availability of the data in near real-time is surely an important added-value. The importance of having near real-time product is confirmed by the recent release (January 2016) of real-time SMOS soil moisture data thanks to the implementation of a new (and faster) algorithm based on artificial neural networks [151].

Of course, ASCAT soil moisture product is also affected by several limitations, some of them that are intrinsic in any remotely sensed soil moisture product:

1) The sensing depth of all satellite sensors is very shallow. The estimated depth for C-band and L-band sensors is around 2 and $7 \mathrm{~cm}$, respectively. In contrast, many applications need a root-zone soil moisture estimate that is not possible to obtain from remote sensing. As already discussed, by modifying the structure of the models, the incorporation of surface measurements can be easily achieved in a data assimilation framework. Alternatively, the approaches developed for estimating root-zone soil moisture from surface observations, e.g., the SWI method [189] or the physically based approach proposed by Manfreda et al. [113] can be used. These approaches are based on the identification of few parameters; thus, potentially suitable for global scale applications. Additionally, some authors combined surface soil moisture with vegetation products to estimate root zone soil moisture (e.g., [47]). For certain applications, SWI has been shown to effectively duplicate the information content of actual root-zone soil moisture observations [140]. However, if surface and root-zone soil moisture levels are decoupled, as usually occurs in very dry conditions [82], the use of satellite measurements can be of limited use.

2) Several factors affect ASCAT soil moisture retrieval accuracy. The main errors are due to topographic complexity, high vegetation density (e.g., pluvial forests), frozen soils, snow cover, and volume scattering in dry soils. Some of these factors are common to any soil moisture product (snow cover and frozen soils) while others are more pronounced for scatterometer-based ASCAT retrievals (i.e., topography and dry soil volume scattering) with respect to competing passive microwave products. Overall, the confounding factors lead to a soil moisture signal characterized by high-frequency noise that, however, can be reduced by using signal processing techniques $[164,166]$.

3) With regards to vegetation, both its structure and water content may have a strong impact on the quality of soil moisture retrievals if not properly accounted for. Recent research by Steele-Dunne et al. [161], [162] and van Emmerik et al. [178] suggests that diurnal variations in vegetation water content may have a stronger impact on backscatter than previously thought. Given the fact that diurnal vegetation effects are currently not accounted for in the TU Wien soil moisture retrieval model, research is needed to quantify these effects and to correct them as far as possible [193]. Recently, an improved estimation of the incidence angle dependency of backscatter [79] has allowed to derive a dynamic vegetation correction facilitating also interannual vegetation variations. First experiments showed promising results over Australia [186] and a global evaluation work is in progress. Overall, there is a need for a renewed look on vegetation effects on microwave observations to explain recent unexpected findings from satellite soil moisture validation studies. Most importantly, there is a need to explain the relatively good performance of the ASCAT soil moisture data products over more densely vegetation compared to C-band passive microwave soil moisture datasets, i.e., AMSR-E [24], [46], [64]. Theoretically, L-band sensors should be the least affected by vegetation [67], but even when compared to L-band SMOS soil moisture data, ASCAT data quality is very good over vegetated areas [121].

4) The spatial resolution of ASCAT product is too coarse for certain local scale applications such as precision agriculture and nutrient transport. However, it should be stressed that this is not the case for all applications. For instance, Brocca et al. [26] and Matgen et al. [117] demonstrated that ASCAT soil moisture products can be effectively employed for improving landslide and flood forecasting in local scale $\left(<50 \mathrm{~km}^{2}\right)$ case studies. In addition, the "temporal stability" of soil moisture spatial patterns allows for the possibility to use coarse resolution data for certain local scale applications, and vice versa [176].

5) The ASCAT soil moisture product is expressed in relative units (percent of saturation) and not as an absolute soil moisture value. This is sometimes perceived as an important issue. Indeed, passive-microwave products are expressed in absolute volumetric terms $\left(\mathrm{m}^{3} / \mathrm{m}^{3}\right)$ which can be directly compared with in situ observation. For the ASCAT soil moisture product, a direct comparison requires the knowledge of soil porosity [195]. We note that ASCAT soil moisture products are also delivered with the soil porosity as ancillary information, but the main unit is in relative terms as global scale soil porosity maps are affected by significant uncertainties. However, this issue is outdated as a large number of studies (e.g., [97], [145], [157]) have demonstrated that the majority of information in soil moisture observations lies in their characterization of relative temporal dynamic and not in their absolute values. Therefore, nearly all current applications require the rescaling of satellite and modeled soil moisture data in a common climatology [29]. As a result, the analysis of satellite soil moisture products in terms of bias has relatively low significance and the units of satellite data should not be considered as a major drawback (or an advantage). Finally, we should underline that even the knowledge of the exact value of soil moisture in volumetric terms does not provide the actual information that is needed for modeling, i.e., the amount of water stored in the soil (e.g., in mm of water). This information can only be obtained from knowledge of the effective sensing depth which is commonly unknown, varying with wetness conditions, and much lower than that simulated by models (i.e., $\sim 1-2 \mathrm{~m}$ depending on climate and soil/land use characteristics). 
By keeping in mind the strengths and limitations of the ASCAT soil moisture product, end-users can make informed decisions about when and where to apply to and what results to expect. However, the full exploitation of satellite soil moisture products in the different applications still need several steps to be carried out as described in the following section.

\section{WAY FORWARD FOR IMPROVING THE OPERATIONAL USE OF (ASCAT) SOIL MOISTURE PRODUCTS}

As mentioned at the beginning, current satellite soil moisture products are mature and accurate enough for being considered as valuable information for real-world applications. Specifically, the ASCAT soil moisture product(s), available in nearreal time since 2007, already demonstrated good agreement with ground observations and having a positive impact in different applications (see Section IV). Even though ASCAT was not designed for soil moisture monitoring in the first place, its well-established technology, calibration, and multi-angle measurement capabilities have allowed us to derive a beneficial and widely recognized soil moisture product. In addition, the Metop Second Generation (Metop-SG) program is currently scheduled until mid-2040s, which has also a scatterometer on the list of foreseen instruments. The next generation scatterometer, so-called SCA, will be very similar to ASCAT, but expected to have improvements in the spatial and radiometric resolution and accuracy [72]. The Metop ASCAT soil moisture product has demonstrated its reliability and is surely ready for being employed in research and operational applications. The continuation of the soil moisture product is also ensured in a long-term perspective by Metop-SG SCA.

Nevertheless, several communities hardly considered these datasets (e.g., for studying slope instability processes and/or epidemic risk assessment) likely due to nonscientific barriers [4] We believe that there is a strong need for promoting collaboration and the exchange between the remote sensing community (data developers) and the different communities of data users in order to fully exploit satellite soil moisture datasets in real-world applications. Capacity building is fundamental to globalizing societal applications of satellite datasets and building consensus on key questions and recommendations [84]. Specifically, there is a strong need for capacity building to better utilize soil moisture products and exploring such data in weather insurance applications when compared to the traditional approaches which are based only on consideration of precipitation data.

In terms of products, we underline that end users are not interested in which technology or microwave band is used for soil moisture retrieval, but mainly that the products meet their requirements in terms of spatial-temporal resolution, spatialtemporal coverage, accuracy, and reliability. The more straightforward approach to accomplish these requirements is based on merging multiplatform satellite products as it is commonly done for precipitation (e.g., in the Global Precipitation Measurement, GPM, mission [85]). A number of examples of such merged products exist already for soil moisture: 1) the ESA Climate Change Initiative (ESA CCI, http://cci.esa.int/), 2) the National Oceanic and Atmospheric Administration
Soil Moisture Operational Product System, NOAA SMOPS (http://www.ospo.noaa.gov/Products/land/smops/), and 3) the EUMETSAT's H SAF (http://hsaf.meteoam.it/). However, further research is needed to optimize the integration of the different products (e.g., data merging versus data fusion approaches) in order to potentially obtain a subdaily soil moisture product with fine spatial resolution (e.g., $\sim 5-10 \mathrm{~km}$ ) [168].

Another fundamental aspect is related to the error characterization of the soil moisture products and specifically its spatialtemporal variability. Indeed, it is a critical aspect when soil moisture datasets are assimilated in hydrological and land surface modelling (e.g., [52], [63], [145]). In very recent years, global scale studies analyzing different products using stateof-the-art techniques were published [59], [77], [165], but the information obtained from these studies must be conveyed in the delivered soil moisture products. It should be noted that the error characterization of more recent products (e.g., AMSR2, SMAP) cannot be reliably determined until $1-2$ years of data is available.

Finally, to provide access to ASCAT soil moisture also for nonexperts, the development of web mapping services, cloud computing facilities, and software and tools that facilitate the downloading and analysis of satellite soil moisture products will be highly beneficial [127], [188]. Many end users are not familiar with using large datasets with uncommon formatting and simply do not take these datasets into account due to technical constraints. Of course, this is not tolerable and clearly asks for a community effort at an international level.

\section{ACKNOWLEDGMENT}

G. Amarnath would like to thank World Meteorological Organization, CGIAR Research Program of Climate Change, Agriculture and Food Security, Water, Land and Ecosystem, and Global Water Partnership for supporting the South Asia Drought Monitoring System.

\section{REFERENCES}

[1] S. Abelen and F. Seitz, "Relating satellite gravimetry data to global soil moisture products via data harmonization and correlation analysis," Remote Sens. Environ., vol. 136, pp. 89-98, 2013, doi:10.1016/j.rse.2013.04.012.

[2] S. Abelen, F. Seitz, R. Abarca-del-Rio, and A. Güntner, "Droughts and floods in the La Plata Basin in soil moisture data and GRACE," Remote Sens., vol. 7, pp. 7324-7349, 2015, doi:10.3390/rs70607324.

[3] W. Abera, L. Brocca, and R. Rigon, "Comparative evaluation of differen satellite rainfall estimation products and bias correction in the Upper Blue Nile (UBN) basin," Atmos. Res., vol. 178/179, pp. 471-483, 2016, doi:10.1016/j.atmosres.2016.04.017.

[4] A. AghaKouchak et al., "Remote sensing of drought: Progress, challenges and opportunities," Rev. Geophys., vol. 53, no. 2, pp. 452-480, 2015, doi: 10.1002/2014RG000456.

[5] C. Albergel et al., "From near-surface to root-zone soil moisture using an exponential filter: An assessment of the method based on in-situ observations and model simulations," Hydrol. Earth Syst. Sci., vol. 12, pp. 1323-1337, 2008, doi:10.5194/hess-12-1323-2008.

[6] C. Alvarez-Garreton, D. Ryu, A. W. Western, W. T. Crow, and D. E. Robertson, "The impacts of assimilating satellite soil moisture into a rainfall-runoff model in a semi-arid catchment," J. Hydrol., vol. 519, pp. 2763-2774, 2014, doi:10.1016/j.jhydrol.2014.07.041.

[7] C. Alvarez-Garreton et al., "Improving operational flood ensemble prediction by the assimilation of satellite soil moisture: Comparison between lumped and semi-distributed schemes," Hydrol. Earth Syst. Sci., vol. 19, pp. 1659-1676, 2015, doi: 10.5194/hess-19-1659-2015. 
[8] A. Al-Yaari et al., "Global-scale comparison of passive (SMOS) and active (ASCAT) satellite based microwave soil moisture retrievals with soil moisture simulations (MERRA-Land)," Remote Sens. Environ., vol. 152, pp. 614-626, 2014, doi:10.1016/j.rse.2014.07.013.

[9] B. Asadieh and N. Y. Krakauer, "Global trends in extreme precipitation: Climate models versus observations," Hydrol. Earth Syst. Sci., vol. 19, pp. 877-891, 2015, doi:10.5194/hess-19-877-2015.

[10] C. Aubrecht, C. D. Elvidge, K. E. Baugh, and S. Hahn, "Identification of wildfire precursor conditions: Linking satellite based fire and soil moisture data," in Computational Vision and Medical Image Processing, Tavares and Natal Jorge Eds. Boca Raton, FL, USA: CRC Press, pp. 347$353,2011$.

[11] G. Balsamo et al., "A revised hydrology for the ECMWF model: Verification from field site to terrestrial water storage and impact in the Integrated Forecast System," J. Hydrol. vol. 10, pp. 623-643, 2009, doi:10.1175/2008JHM1068.1.

[12] G. Balsamo et al., "ERA-Interim/Land: a global land surface reanalysis data set," Hydrol. Earth Syst. Sci., vol. 19, pp. 389-407, 2015, doi:10.5194/hess-19-389-2015.

[13] Z. Bartalis, K. Scipal, and W. Wagner, "Azimuthal anisotropy of scatterometer measurements over land," IEEE Trans. Geosci. Remote Sens., vol. 44, no. 8, pp. 2083-2092, Aug. 2006, doi:10.1109/TGRS. 2006.872084.

[14] Z. Bartalis et al., "Initial soil moisture retrievals from the METOP-A Advanced Scatterometer (ASCAT)," Geophys. Res. Lett., vol. 34, 2007, Art. no. L20401, doi:10.1029/2007GL031088.

[15] H. E. Beck, R. A. de Jeu, J. Schellekens, H. E. Beck, A. I. J. M. van Dijk and, L. A. Bruinjnzeel, "Improving curve number based storm runoff estimates using soil moisture proxies," IEEE J. Sel. Top. Appl. Earth Observ., vol. 2, no. 4, pp. 250-259, Dec. 2009, doi:10.1109/JSTARS.2009. 2031227.

[16] A.-A. Belal, H. R. El-Ramady, E. S. Mohamed, and A. M. Saleh, "Drought risk assessment using remote sensing and GIS techniques," Arab. J. Geosci., vol. 7, pp. 35-53, 2012, doi:10.1007/s12517-012-07072.

[17] M. F. Bierkens et al., "Hyper-resolution global hydrological modelling: What is next? Everywhere and locally relevant," Hydrol. Process., vol. 29, no. 2, pp. 310-320, 2015, doi:10.1002/hyp.10391.

[18] B. Bisselink, E. Van Meijgaard, A. J. Dolman, and R. A. M. De Jeu, "Initializing a regional climate model with satellite-derived soil moisture," J. Geophys. Res., vol. 116, no, D2, 2011, doi:10.1029/2010JD014534.

[19] M. Bittelli, R. Valentino, F. Salvatorelli, and PR. Pisa, "Monitoring soilwater and displacement conditions leading to landslide occurrence in partially saturated clays," Geomorphology, vol. 173/174, pp. 161-173, 2012, doi:10.1016/j.geomorph.2012.06.006

[20] H. R. Bogena et al., "Emerging methods for noninvasive sensing of soil moisture dynamics from field to catchment scale: A review," WIREs Water, vol. 2 , no. 6, pp. 635-647, 2015, doi:10.1002/wat2.1097.

[21] J. D. Bolten and W. T. Crow, "Improved prediction of quasi-global vegetation conditions using remotely-sensed surface soil moisture," Geophys. Res. Lett., vol. 39, 2012, Art. no. L19406, doi:10.1029/2012GL053470.

[22] L. Brocca, F. Melone, T. Moramarco, and R. Morbidelli, "Antecedent wetness conditions based on ERS scatterometer data," J. Hydrol., vol. 364, no. 1/2, pp. 73-87, 2009, doi:10.1016/j.jhydrol.2008.10.007.

[23] L. Brocca et al., "Improving runoff prediction through the assimilation of the ASCAT soil moisture product," Hydrol. Earth Syst. Sci., vol. 14, pp. 1881-1893, 2010, doi:10.5194/hess-14-1881-2010.

[24] L. Brocca et al., "Soil moisture estimation through ASCAT and AMSR-E sensors: An intercomparison and validation study across Europe," Remote Sens. Environ., vol. 115, pp. 3390-3408, 2011, doi:10.1016/j.rse.2011.08.003.

[25] L. Brocca, T. Moramarco, F. Melone, W. Wagner, S. Hasenauer, and S. Hahn, "Assimilation of surface and root-zone ASCAT soil moisture products into rainfall-runoff modelling," IEEE Trans. Geosci. Remote Sens., vol. 50, no. 7, pp. 2542-2555, 2012, doi:10.1109/TGRS.2011.2177468.

[26] L. Brocca, F. Ponziani, T. Moramarco, F. Melone, N. Berni, and W. Wagner, "Improving landslide forecasting using ASCAT-derived soil moisture data: A case study of the Torgiovannetto landslide in central Italy, Remote Sens., vol. 4, no. 5, pp. 1232-1244, 2012, doi:10.3390/rs4051232.

[27] L. Brocca, F. Melone, T. Moramarco, and W. Wagner, "A new method for rainfall estimation through soil moisture observations," Geophys. Res. Lett., vol. 40, no. 5, pp. 853-858, 2013, doi:10.1002/grl.50173.

[28] L. Brocca et al., "Soil as a natural rain gauge: Estimating global rainfall from satellite soil moisture data," J. Geophys. Res., vol. 119, pp. 51285141, 2014, 2014JD021489, doi:10.1002/2014JD021489.
[29] L. Brocca, G. Zucco, H. Mittelbach, T. Moramarco, and S. I. Seneviratne, "Absolute versus temporal anomaly and percent of saturation soil moisture spatial variability for six networks worldwide," Water Resour. Res., vol. 50, no. 7, pp. 5560-5576, 2014, doi:10.1002/2014WR015684.

[30] L. Brocca et al., "Rainfall estimation from in situ soil moisture observations at several sites in Europe: An evaluation of SM2RAIN algorithm," J. Hydrol. Hydromech., vol. 63, no. 3, pp. 201-209, 2015, doi:10.1515/johh-2015-0016.

[31] L. Brocca, C. Massari, L. Ciabatta, W. Wagner, and A. Stoffelen, "Remote sensing of terrestrial rainfall from Ku-band scatterometers," IEEE J. Sel. Top. Appl. Earth Observ., vol. 9, no. 1, pp. 533-539, Jan. 2016, doi:10.1109/JSTARS.2015.2508065.

[32] L. Brocca et al., "Rainfall estimation by inverting SMOS soil moisture estimates: A comparison of different methods over Australia," J. Geophys. Res., vol. 121, pp. 12062-12079, 2016, doi:10.1002/2016JD025382

[33] G. Calamita, A. Perrone, L. Brocca, B. Onorati, and S. Manfreda, "Field test of a multi-frequency electromagnetic induction sensor for soil moisture monitoring in southern Italy test sites," J. Hydrol., vol. 529, no. 1, pp. 316-329, 2015, doi:10.1016/j.jhydrol.2015.07.023.

[34] S. Camici, L. Brocca, F. Melone, and T. Moramarco, "Impact of climate change on flood frequency using different climate models and downscaling approaches," J. Hydrol. Eng., vol. 19, no. 8, 2014, Art. no. 04014002, doi:10.1061/(ASCE)HE.1943-5584.0000959.

[35] V. Capecchi and L. Brocca, "A simple assimilation method to ingest satellite soil moisture into a limited-area NWP model," Meteorol. Z., vol. 23, no. 2, pp. 105-121, 2014, doi:10.1127/0941-2948/2014/0585.

[36] M. Carrera, S. Bélair, and B. Bilodeau, "The Canadian land data assimilation system (CaLDAS): Description and synthetic evaluation study," J. Hydrometeorol., vol. 16, pp. 1293-1314, 2015, doi:10.1175/JHM-D14-0089.1.

[37] A. Ceballos, K. Scipal, W. Wagner, and J. Martínez-Fernández, "Validation of ERS scatterometer-derived soil moisture data in the central part of the Duero Basin," Hydrol. Process., vol. 19, pp. 1549-1566, 2005, doi:10.1002/hyp.5585.

[38] C. Champagne, A. Davidson, P. Cherneski, J. L'Heureux, and T. Hadwen, "Monitoring agricultural risk in Canada using L-band passive microwave soil moisture from SMOS," J. Hydrometeorol., vol. 16, no. 1, pp. 5-18, 2015, doi:10.1175/JHM-D-14-0039.1.

[39] F. Chen, W. T. Crow, P. J. Starks, and D. N. Moriasi, "Improving hydrologic predictions of a catchment model via assimilation of surface soil moisture," Adv. Water Resour., vol. 34, pp. 526-536, 2011, doi:10.1016/j.advwatres.2011.01.011.

[40] F. Chen, W. T. Crow, and D. Ryu, "Dual forcing and state correction via soil moisture assimilation for improved rainfall-runoff modeling," $J$. Hydrometeorol., vol. 15, no. 5, pp. 1832-1848, 2014, doi: 10.1175/JHMD-14-0002.1.

[41] T. Chen et al., "Advantages of using microwave satellite soil moisture over gridded precipitation products and land surface model output in assessing regional vegetation water availability and growth dynamics for a lateral inflow receiving landscape," Remote Sens., vol. 8, no. 5, p. 428, 2016, doi:10.3390/rs8050428.

[42] E. Chirebvu, M. J. Chimbari, B. N. Ngwenya, and B. Sartorius, "Clinical malaria transmission trends and its association with climatic variables in Tubu Village, Botswana: A retrospective analysis," PloS One, vol. 11, no. 3, 2016, Art. no. e0139843, doi:10.1371/journal.pone.0139843.

[43] L. Ciabatta et al., "Integration of satellite soil moisture and rainfall observations over the Italian territory," J. Hydrometeorol., vol. 16, no. 3, pp. 1341-1355, 2015, doi:10.1175/JHM-D-14-0108.1.

[44] L. Ciabatta et al., "Rainfall-runoff modelling by using SM2RAINderived and state-of-the-art satellite rainfall products over Italy," Int. J. Appl. Earth Obs. Geoinf., vol. 48, pp. 163-173, 2016, doi:10.1016/j.jag.2015.10.004.

[45] R. Crapolicchio et al., "The scatterometer instrument competence centre (SCIRoCCo): Project's activities and first achievements," in Proc. Eur. Space Agency Living Planet Symp., 2016, Prague, Czech Republic, pp. 9 13, May 2016.

[46] W. T. Crow and X. Zhan, "Continental-scale evaluation of remotely sensed soil moisture products," IEEE Geosci. Remote Sens. Lett., vol. 4, no. 3, pp. 451-455, 2007, doi:10.1109/LGRS.2007.896533.

[47] W. T. Crow, W. P. Kustas, and J. Prueger, "Monitoring root-zone soil moisture through the assimilation of a thermal remote sensing-based soil moisture proxy into a water balance model," Remote Sens. Environ., vol. 112, pp. 1268-1281, 2008, doi:10.1016/j.rse.2006.11.033.

[48] W. T. Crow, G. F. Huffman, R. Bindlish, and T. J. Jackson, "Improving satellite rainfall accumulation estimates using spaceborne soil 
moisture retrievals," J. Hydrometeorol., vol. 10, pp. 199-212, 2009, doi:10.1175/2008JHM986.1.

[49] W. T. Crow and D. Ryu, "A new data assimilation approach for improving runoff prediction using remotely-sensed soil moisture retrievals," Hydrol. Earth Syst. Sci., vol. 13, pp. 1-16, 2009, doi:10.5194/hess-13-1-2009.

[50] W. T. Crow, M. J. van Den Berg, G. J. Huffman, and T. Pellarin, "Correcting rainfall using satellite-based surface soil moisture retrievals: The soil moisture analysis rainfall tool (SMART)," Water Resour. Res., vol. 47, 2011, Art. no. W08521, doi:10.1029/2011WR010576.

[51] W. T. Crow, S. V. Kumar, and J. D. Bolten, "On the utility of land surface models for agricultural drought monitoring," Hydrol. Earth Syst. Sci., vol. 16, pp. 3451-3460, 2012, doi:10.5194/hess-16-3451-2012.

[52] W. T. Crow and M. T. Yilmaz, "The auto-tuned land assimilation system (ATLAS)," Water Resour. Res., vol. 50, no. 1, pp. 371-384, 2014, doi:10.1002/2013WR0145502014.

[53] A. Dai, "Increasing drought under global warming in observations and models," Nature Climate Change, vol. 3, pp. 52-58, 2013, doi:10.1038/nclimate1633.

[54] R. de Jeu, W. Wagner, T. Holmes, H. Dolman, N. C. van de Giesen, and J. Friesen, "Global soil moisture patterns observed by space borne microwave radiometers and scatterometers," Surv. Geophys., vol. 29, pp. 399-420, 2008, doi:10.1007/s10712-008-9044-0.

[55] G. J. M. de Lannoy, P. de Rosnay, and R. H. Reichle, "Soil moisture data assimilation," in Handbook of Hydrometeorological Ensemble Forecasting, Q. Duan, F. Pappenberger, J. Thielen, A. Wood, H. Cloke, J. C. Schaake Eds. New York, NY, USA: Springer-Verlag, 2016.

[56] P. de Rosnay, M. Drusch, D. Vasiljevic, G. Balsamo, C. Albergel, and L. Isaksen, "A simplified extended Kalman filter for the global operational soil moisture analysis at ECMWF," Quart. J. Roy. Meteorol. Soc., vol. 139, no. 674, pp. 1199-1213, 2013, doi:10.1002/qj.2023.

[57] P. de Rosnay, G. Balsamo, C. Albergel, J. Muñoz-Sabater, and L. Isaksen, "Initialisation of land surface variables for numerical weather prediction," Surv. Geophys., vol. 35, no. 3, pp. 607-621, 2014, doi:10.1007/s10712-012-9207-x.

[58] I. Dharssi, K. Bovis, B. Macpherson, and C. Jones, "Operational assimilation of ASCAT surface soil wetness at the Met Office," Hydrol. Earth Syst. Sci., vol. 15, pp. 2729-2746, 2011, doi:10.5194/hess-15-2729-2011.

[59] W. A. Dorigo et al., "Error characterisation of global active and passive microwave soil moisture datasets," Hydrol. Earth Syst. Sci., vol. 14, no. 12, pp. 2605-2616, 2010, doi:10.5194/hess-14-2605-2010.

[60] W. A. Dorigo et al., "The international soil moisture network: A data hosting facility for global in situ soil moisture measurements," Hydrol. Earth Syst. Sci., vol. 15, pp. 1675-1698, 2011, doi:10.5194/hess-151675-2011.

[61] W. A. Dorigo et al., "Global automated quality control of in situ soil moisture data from the international soil moisture network," Vadose Zone J., vol. 12, no. 3, 2013, doi:10.2136/vzj2012.0097.

[62] W. A. Dorigo et al., "Evaluation of the ESA CCI soil moisture product using ground-based observations," Remote Sens. Environ., vol. 162, pp. 380-395, 2015, doi:10.1016/j.rse.2014.07.023.

[63] C. S. Draper, R. H. Reichle, G. J. M. De Lannoy, and Q. Liu, "Assimilation of passive and active microwave soil moisture retrievals," Geophys. Res. Lett., vol. 39, 2012, Art. no. L04401, doi:10.1029/2011GL050655.

[64] C. Draper, R. Reichle, R. de Jeu, V. Naeimi, R. Parinussa, and W. Wagner, "Estimating root mean square errors in remotely sensed soil moisture over continental scale domains," Remote Sens. Environ., vol. 137, pp. 288298, 2013, doi:10.1016/j.rse.2013.06.013.

[65] E. A. Eltahir, "A soil moisture-rainfall feedback mechanism: 1. Theory and observations," Water Resour. Res., vol. 34, no. 4, pp. 765-776, 1998, doi:10.1029/97WR03499.

[66] M. Enenkel et al., "A combined satellite-derived drought indicator to support humanitarian aid organizations," Remote Sens., vol. 8, no. 4, p. 340, 2016, doi: 10.3390/rs8040340.

[67] D. Entekhabi et al., "The soil moisture active passive (SMAP) mission," Proc. IEEE, vol. 98, no. 5, pp. 704-716, 2010, doi:10.1109/JPROC. 2010.2043918.

[68] J. K. Entin, A. Robock, K. Y. Vinnikov, S. E. Hollinger, S. Liu, and A. Namkhai, "Temporal and spatial scales of observed soil moisture variations in the extratropics," J. Geophys. Res., vol. 105, pp. 1186511877, 2000, doi:10.1029/2000JD900051.

[69] V. M. Escobar, M. Srinivasan, and S. D. Arias, “Improving NASA's Earth observation systems and data programs through the engagement of mission early adopters," in Earth Science Satellite Applications, F. Hossain Ed. Cham, Switzerland: Springer International Publishing, pp. 223-267, 2016, doi:10.1007/978-3-319-33438-7_9.
[70] L. Feyen, R. Dankers, K. Bódis, P. Salamon, and J. I. Barredo, "Fluvial flood risk in Europe in present and future climates," Climate Chang., vol. 112, no. 1, pp. 47-62, 2012, doi:10.1007/s10584-011$0339-7$.

[71] J. Figa-Saldana, J. J. W. Wilson, E. Attema, R. Gelsthorpe, M. R. Drinkwater, and A. Stoffelen, "The advanced scatterometer (ASCAT) on the meteorological operational (MetOp) platform: A follow on for European wind scatterometers," Canadian J. Remote Sens., vol. 28, no. 3, pp. 404-412, 2002. [Online]. Available: https://doi.org/10.5589/m02035

[72] F. Fois, C. C. Lin, M. Loiselet, K. Scipal, A. Stoffelen, and J. J. W. Wilson, "The Metop second generation scatterometer, in Proc. Int. Geosci. Remote Sensing Symp., 2014, pp. 1-4.

[73] T. E. Franz, T. Wang, W. Avery, C. Finkenbiner, and L. Brocca, "Combined analysis of soil moisture measurements from roving and fixed cosmic-ray neutron probes for multi-scale real-time monitoring," Geophys. Res. Lett., vol. 42, no. 9, pp. 3389-3396, 2015, doi: 10.1002/2015GL063963.

[74] R. V. Gelsthorpe, E. Schied, and J. J. W. Wilson, "ASCAT-Metop's advanced scatterometer," ESA Bull., vol. 102, pp. 19-27, 2000.

[75] J. W. Godt, R. L. Baum, and A. F. Chleborad, "Rainfall characteristics for shallow landsliding in Seattle," Earth Surface Processes Landforms, vol. 31, pp. 97-110, 2006, doi:10.1002/esp.1237.

[76] A. Gruber and W. T. Crow, "The potential of 2D Kalman filtering for soil moisture data assimilation," Remote Sens. Environ., vol. 171, pp. 137148, 2015, doi:10.1016/j.rse.2015.10.019.

[77] A. Gruber, C.-H. Su, S. Zwieback, W. Crow, W. Dorigo, and W. Wagner, "Recent advances in (soil moisture) triple collocation analysis," Int. J. Appl. Earth Observation Geoinf., vol. 45, pp. 200-211, 2016, doi:10.1016/j.jag.2015.09.002.

[78] B. P. Guillod, B. Orlowsky, D. G. Miralles, A. J. Teuling, and S. I. Seneviratne, "Reconciling spatial and temporal soil moisture effects on afternoon rainfall," Nature Commun., vol. 6, 2015, Art. no. 6443, doi: $10.1038 /$ ncomms 7443.

[79] S. Hahn, C. Reimer, M. Vreugdenhil, T. Melzer, and W. Wagner, "Dynamic characterization of the incidence angle dependency of backscatter over land using Metop ASCAT," IEEE Trans. Geosci. Remote Sens., to be published.

[80] E. Han, W. T. Crow, T. Holmes, and J. Bolten, "Benchmarking a soil moisture data assimilation system for agricultural drought monitoring," $J$. Hydrometeorol., vol. 15, no. 3, pp. 1117-1134, 2014, doi:10.1175/JHMD-13-0125.1.

[81] R. M. Hirsch and S. A. Archfield, "Flood trends: Not higher but more often," Nature Climate Change, vol. 5, pp. 198-199, 2015, doi:10.1038/nclimate2551.

[82] M. Hirschi, B. Mueller, W. Dorigo, and S. I. Seneviratne, "Using remotely sensed soil moisture for land-atmosphere coupling diagnostics: The role of surface vs. root-zone soil moisture variability," Remote Sens. Environ., vol. 154, pp. 246-252, 2014, doi:10.1016/j.rse.2014.08.030.

[83] J. W. Hopmans, D. R. Nielsen, and K. L. Bristow, "How useful are small-scale soil hydraulic property measurements for large-scale vadose zone modeling?" in Environmental Mechanics: Water, Mass and Energy Transfer in the Biosphere: The Philip Volume, P. A.C. Raats, D. Smiles, and A. W. Warrick Eds. Washington, DC, USA: American Geophysical Union, pp. 247-258, 2002, doi:10.1029/129GM20.

[84] F. Hossain et al., "A global capacity building vision for societal applications of Earth observing systems and data: Key questions and recommendations," Bull. Amer. Meteor. Soc., to be published, doi:10.1175/BAMSD-15-00198.1.

[85] A. Y. Hou et al., "The global precipitation measurement (GPM) mission," Bull. Amer. Meteor. Soc., vol. 95, no. 5, pp. 701-722, 2014 doi:10.1175/BAMS-D-13-00164.1.

[86] A. V. M. Ines, N. N. Das, J. W. Hansen, and E. G. Njoku, "Assimilation of remotely sensed soil moisture and vegetation with a crop simulation model for maize yield prediction," Remote Sens. Environ., vol. 138, pp. 149-164, 2013, doi:10.1016/j.rse.2013.07.018.

[87] IPCC (Intergovernmental Panel on Climate Change), Managing the Risks of Extreme Events and Disasters to Advance Climate Change Adaptation: Special Report of the Intergovernmental Panel on Climate Change, Field, C. B. Ed. Cambridge, U.K.: Cambridge Univ. Press, 2012.

[88] E. Janssen, D. J. Wuebbles, K. E. Kunkel, S. C. Olsen, and A. Goodman, "Observational-and model-based trends and projections of extreme precipitation over the contiguous United States," Earth's Future, vol. 2, no. 2, pp. 99-113, 2014, doi:10.1002/2013EF000185. 
[89] B. Jongman et al., "Increasing stress on disaster-risk finance due to large floods," Nature Climate Change, vol. 4, no. 4, pp. 264-268, 2014, doi:10.1038/nclimate2124.

[90] Y. H. Kerr, P. Waldteufel, J.-P. Wigneron, J. Martinuzzi, J. Font, and M. Berger, "Soil moisture retrieval from space: The soil moisture and ocean salinity (SMOS) mission," IEEE Trans. Geosci. Remote Sens., vol. 39, no. 8, pp. 1729-1735, 2001, doi:10.1109/36.942551.

[91] Y. H. Kerr et al., "The SMOS soil moisture retrieval algorithm," IEEE Trans. Geosci. Remote, vol. 50, no. 5, pp. 1384-1403, May 2012, doi:10.1109/TGRS.2012.2184548.

[92] C. Kidd and V. Levizzani, "Status of satellite precipitation retrievals," Hydrol. Earth Syst. Sci., vol. 15, pp. 1109-1116, 2011, doi:10.5194/hess15-1109-2011.

[93] S. Kim, Y. Y. Liu, F. M. Johnson, R. M. Parinussa, and A. Sharma, "A global comparison of alternate AMSR2 soil moisture products: Why do they differ?" Remote Sens. Environ., vol. 161, pp. 43-62, 2015, doi:10.1016/j.rse.2015.02.002.

[94] R. D. Koster and M. J. Suarez, "Soil moisture memory in climate models," J. Hydrometeorol., vol. 2, no. 6, pp. 558-570, 2001, doi:10.1175/15257541(2001)002<0558:SMMICM > 2.0.CO;2.

[95] R. D. Koster et al., "Regions of strong coupling between soil moisture and precipitation," Science, vol. 305, pp. 1138-1140, 2004, doi:10.1126/science.1100217.

[96] R. D. Koster et al., "Realistic initialization of land surface states: impacts on subseasonal forecast skill," J. Hydrometeorol., vol. 5, no. 6, pp. 10491063, 2004, doi:10.1175/JHM-387.1.

[97] R. D. Koster, Z. Guo, R. Yang, P. A. Dirmeyer, K. Mitchell, and M. J. Puma, "On the nature of soil moisture in land surface models," J. Climate, vol. 22, pp. 4322-4335, 2009, doi:10.1175/2009JCLI2832.1.

[98] R. D. Koster, S. P. P. Mahanama, B. Livneh, D. Lettenmaier, and R. H. Reichle, "Skill in Streamflow forecasts derived from large-scale estimates of soil moisture and snow," Nature Geosci., vol. 3, pp. 613-616, 2010, doi:10.1038/ngeo944.

[99] R. D. Koster et al., "Contribution of land surface initialization to subseasonal forecast skill: First results from a multi-model experiment, Geophys. Res. Lett., vol. 37, 2010, Art. no. L02402, doi:10.1029/2009GL041677.

[100] R. D. Koster, G. K. Walker, S. P. P. Mahanama, and R. H. Reichle, "Soil moisture initialization error and subgrid variability of precipitation in seasonal streamflow forecasting," J. Hydrometeorol., vol. 15, pp. 69-88, 2014, doi:10.1175/JHM-D-13-050.1.

[101] R. D. Koster, L. Brocca, W. T. Crow, M. S. Burgin, and G. J. M. De Lannoy, "Precipitation estimation using L-band and C-band soil moisture retrievals," Water Resour. Res., vol. 52, no. 9, pp. 7213-7225, 2016, doi:10.1002/2016WR019024.

[102] P. A. Kucera et al., "Precipitation from space: Advancing earth system science," Bull. Amer. Meteorol. Soc., vol. 94, pp. 365-375, 2013, doi:10.1175/BAMS-D-11-00171.1.

[103] W. P. Kustas and M. Anderson, "Advances in thermal infrared remote sensing for land surface modelling," Agricultural. Forest Meteorol., vol. 149, pp. 2071-2081, 2009, doi:10.1016/j.agrformet.2009. 05.016 .

[104] T. Lacava et al., "Improving soil wetness variations monitoring from passive microwave satellite data: The case of April 2000 Hungary flood," Remote Sens. Environ., vol. 96, no. 2, pp. 135-148, 2005, doi:10.1016/j.rse.2005.01.015.

[105] K. M. Larson, E. E. Small, E. D. Gutmann, A. L. Bilich, J. J. Braun, and V. U. Zavorotny, "Use of GPS receivers as a soil moisture network for water cycle studies," Geophys. Res. Lett., vol. 35, no. 24, 2008, Art. no. L24405, doi:10.1029/2008GL036013.

[106] H. Lievens et al., "SMOS soil moisture assimilation for improved hydrologic simulation in the Murray Darling Basin," Remote Sens. Environ., vol. 168, pp. 146-162, 2015, doi:10.1016/j.rse.2015. 06.025 .

[107] Y. Y. Liu et al., "Developing an improved soil moisture dataset by blending passive and active microwave satellite-based retrievals," $\mathrm{Hydrol}$. Earth Syst. Sci., vol. 15, pp. 425-436, 2011, doi:10.5194/hess-15-4252011.

[108] Q. Liu et al., "The contributions of precipitation and soil moisture observations to the skill of soil moisture estimates in a land data assimilation system, J. Hydrometeorol., vol. 12, pp. 750-765, 2011, doi:10.1175/JHM-D-10-05000.1.

[109] Y. Y. Liu et al., "Trend-preserving blending of passive and active microwave soil moisture retrievals," Remote Sens. Environ., vol. 123, pp. 280-297, 2012, doi:10.1016/j.rse.2012.03.014.
[110] R. Lorenz et al., "Influence of land-atmosphere feedbacks on temperature and precipitation extremes in the GLACE-CMIP5 ensemble," J. Geophys. Res., vol. 121, pp. 607-623, 2016, doi:10.1002/2015JD024053.

[111] J.-F. Mahfouf, P. Viterbo, H. Douville, A. Beljaars, and S. Saarinen, "A revised land-surface analysis scheme in the integrated forecasting system," ECMWF Newsletter, vol. 88, 2000, pp. 8-13.

[112] Y. Malbéteau, O. Merlin, B. Molero, C. Rüdiger, and S. Bacon, "DisPATCh as a tool to evaluate coarse-scale remotely sensed soil moisture using localized in situ measurements: Application to SMOS and AMSRE data in Southeastern Australia," Int. J. Appl. Earth Observation Geoinf., vol. 45, pp. 221-234, 2016, doi:10.1016/j.jag.2015.10.002.

[113] S. Manfreda, L. Brocca, T. Moramarco, F. Melone, and J. Sheffield, "A physically based approach for the estimation of root-zone soil moisture from surface measurements," Hydrol. Earth Syst. Sci., vol. 18, pp. 1199 1212, 2014, doi:10.5194/hess-18-1199-2014.

[114] B. Martens, D. Miralles, H. Lievens, D. Fernandez-Prieto, and Verhoest, N., "Improving terrestrial evaporation estimates over continental Australia through assimilation of SMOS soil moisture," Int. J. Appl. Earth Observation Geoinf., vol. 48, pp. 146-162, 2015, doi:10.1016/j.jag.2015.09.012.

[115] C. Massari, L. Brocca, T. Moramarco, Y. Tramblay, and J.-F. D. Lescot, "Potential of soil moisture observations in flood modelling: Estimating initial conditions and correcting rainfall," Adv. Water Resour., vol. 74, pp. 44-53, 2014, doi:10.1016/j.advwatres.2014.08.004.

[116] C. Massari, L. Brocca, A. Tarpanelli, and T. Moramarco, "Data assimilation of satellite soil moisture into rainfall-runoff modelling: A complex recipe?" Remote Sens., vol. 7, no. 9, pp. 11403-11433, 2015, doi:10.3390/rs70911403.

[117] P. Matgen et al., "Can ASCAT-derived soil wetness indices reduce predictive uncertainty in well-gauged areas? A comparison with in situ observed soil moisture in an assimilation application," Adv. Water Resour. vol. 44, pp. 49-65, 2012, doi:10.1016/j.advwatres.2012.03.022.

[118] D. G. Miralles, T. R. H. Holmes, R. A. M. De Jeu, J. H. Gash, A. G. C. A. Meesters, and A. J. Dolman, "Global land-surface evaporation estimated from satellite-based observations," Hydrol. Earth Syst. Sci., vol. 15, pp. 453-469, 2011, doi:10.5194/hess-15-453-2011.

[119] D. G. Miralles, M. V. den Berg, A. J. Teuling, and R. D. Jeu, "Soil moisture-temperature coupling: A multiscale observational analysis," Geophys. Res. Lett., vol. 39, no. 21, 2012, doi:10.1029/2012GL053703.

[120] D. G. Miralles, A. J. Teuling, C. C. van Heerwaarden, and J. V. G. de Arellano, "Mega-heatwave temperatures due to combined soil desiccation and atmospheric heat accumulation," Nature Geosci., vol. 7, no. 5, pp. 345-349, 2014, doi:10.1038/ngeo2141.

[121] K. Miyaoka et al., "Triple collocation analysis of soil moisture from Metop-A ASCAT and SMOS against JRA-55 and ERA-Interim," EE J. Sel. Top. Appl. Earth Observ., to be published.

[122] I. Mladenova, V. Lakshmi, J. P. Walker, D. G. Long, and R. De Jeu, "An assessment of QuikSCAT Ku-band scatterometer data for soil moisture sensitivity," IEEE Geosci. Remote. S., vol. 6, no. 4, pp. 640-643, 2009, doi:10.1109/LGRS.2009.2021492.

[123] E. Montosi, S. Manzoni, A. Porporato, A. Montanari, "An ecohydrological model of malaria outbreaks," Hydrol. Earth Syst. Sci., vol. 16, no. 8 , pp. 2759-2769, 2012, doi:10.5194/hess-16-2759-2012.

[124] M. S. Moran, B. Doorn, V. Escobar, and M. E. Brown, "Connecting NASA science and engineering with earth science applications," J. Hydrometeorol., vol. 16, no. 1, pp. 473-483, 2015, doi:10.1175/JHM-D14-0093.1.

[125] R. Morbidelli, C. Corradini, and R. S. Govindaraju, "A field-scale infiltration model accounting for spatial heterogeneity of rainfall and soil saturated hydraulic conductivity," Hydrol. Process., vol. 20, no. 7, pp. 14651481, 2006, doi:10.1002/hyp.5943.

[126] A. A. Muñoz et al., "Patterns and drivers of Araucaria araucana forest growth along a biophysical gradient in the northern Patagonian Andes: Linking tree rings with satellite observations of soil moisture," Austral. Ecol., vol. 39, pp. 158-169, 2014, doi:10.1111/aec.12054.

[127] J. Muñoz-Sabater, A. Al Bitar, and L. Brocca, "Soil moisture retrievals based on active and passive microwave data: State-of-the-art and operational applications," in Satellite Soil Moisture Retrievals: Techniques \& Applications, G. P. Petropoulos, P. Srivastava, Y. Kerr Eds. Amsterdam, The Netherland: Elsevier, Ch. 18, pp. 351-378, 2016, doi:10.1016/B9780-12-803388-3.00018-8.

[128] V. Naeimi, K. Scipal, Z. Bartalis, S. Hasenauer, and W. Wagner, "An improved soil moisture retrieval algorithm for ERS and METOP scatterometer observations," IEEE Trans. Geosci. Remote Sens., vol. 47, no. 7, pp. 1999-2013, 2009, doi:10.1109/TGRS.2008.2011617. 
[129] V. Naeimi, P. Leinenkugel, D. Sabel, W. Wagner, H. Apel, and C. Kuenzer, "Evaluation of soil moisture retrieval from the ERS and Metop scatterometers in the lower Mekong Basin," Remote Sens., vol. 5, no. 4, pp. 1603-1623, 2013, doi:10.3390/rs5041603.

[130] T. E. Ochsner et al., "State of the art in large-scale soil moisture monitoring," Soil Sci. Soc. Amer. J., vol. 77, no. 6, pp. 1888-1919, 2013, doi:10.2136/sssaj2013.03.0093.

[131] R. Orth and S. I. Seneviratne, "Using soil moisture forecasts for sub-seasonal summer temperature predictions in Europe," Climate Dyn., vol. 43, no. 12, pp. 3403-3418, 2014, doi:10.1007/s00382-0142112-x.

[132] S. Paloscia, S. Pettinato, E. Santi, C. Notarnicola, L. Pasolli, and A. Reppucci, "Soil moisture mapping using Sentinel-1 images: Algorithm and preliminary validation," Remote Sens. Environ., vol. 134, pp. 234 248, 2013, doi:10.1016/j.rse.2013.02.027.

[133] J. Parajka, V. Naemi, G. Bloschl, W. Wagner, R. Merz, and K. Scipal, "Assimilating scatterometer soil moisture data into conceptual hydrologic models at coarse scales," Hydrol. Earth Syst. Sci., vol. 10, pp. 353-368, 2006, doi:10.5194/hess-10-353-2006.

[134] C. Paulik, W. Dorigo, W. Wagner, and R. Kidd, "Validation of the ASCAT soil water index using in situ data from the international soil moisture network," Int. J. Appl. Earth Observation Geoinf., vol. 30, pp. 1-8, 2014, doi:10.1016/j.jag.2014.01.007.

[135] T. Pellarin, S. Louvet, C. Gruhier, G. Quantin, and C. Legout, "A simple and effective method for correcting soil moisture and precipitation estimates using AMSR-E measurements," Remote Sens. Environ., vol. 136, pp. 28-36, 2013, doi:10.1016/j.rse.2013.04.011.

[136] J. Peters et al., "On the relation between soil moisture dynamics and the geographical distribution of Culicoides imicola," Ecohydrology, vol. 7, no. 2, pp. 622-632, 2014, doi:10.1002/eco.1383.

[137] M. Piles et al., "On the synergy of SMOS and Terra/Aqua MODIS: high resolution soil moisture maps in near real-time," in Proc. Int. Geosci. Remote Sens. Symp., 2013, pp. 3423-3426, doi:10.1109/IGARSS. 2013.6723564.

[138] M. Piles et al., "A downscaling approach for SMOS land observations: Evaluation of high-resolution soil moisture maps over the Iberian Peninsula," IEEE J. Sel. Topics Appl. Earth Observ., vol. 7, no. 9, pp. 38453857, Sep. 2014, doi:10.1109/JSTARS.2014.2325398.

[139] Y. Qi, P. E. Dennison, J. Spencer, and D. Riano, "Monitoring live fuel moisture using soil moisture and remote sensing proxies," Fire Ecol., vol. 8, no. 3, pp. 71-87, 2012, doi:10.4996/fireecology. 0803071.

[140] J. Qiu, W. T. Crow, G. S. Nearing, X. Mo, and S. Liu, "The impact of vertical measurement depth on the information content of soil moisture times series data," Geophys. Res. Lett., vol. 41, pp. 4997-5004, 2014, doi:10.1002/2014GL060017.

[141] P. Rahimzadeh-Bajgiran and A. Berg, "Soil moisture retrievals using optical/TIR methods," in Satellite Soil Moisture Retrievals: Techniques \& Applications, G. P. Petropoulos, P. Srivastava, Y. Kerr Eds. Amsterdam, The Netherlands: Elsevier, Ch. 3, pp. 47-72, 2016, doi:10.1016/B9780-12-803388-3.00003-6.

[142] A. Rahmani, S. Golian, and L. Brocca, "Multiyear monitoring of soil moisture over Iran through satellite and reanalysis soil moisture products," Int. J. Appl. Earth Observation Geoinf., vol. 48, no. 8595, 2016, doi:10.1016/j.jag.2015.06.009.

[143] R. L. Ray, J. M. Jacobs, and M. H. Cosh, "Landslide susceptibility mapping using downscaled AMSR-E soil moisture: A case study from Cleveland Corral, California, US," Remote Sens. Environ., vol. 114, no. 11, pp. 2624-2632, 2010, doi:10.1016/j.rse.2010.05.033.

[144] R. L. Ray, J. M. Jacobs, and T. P. Ballestero, "Regional landslide susceptibility: Spatiotemporal variations under dynamic soil moisture conditions," Nature Hazards, vol. 59, pp. 1317-1337, 2011, doi:10.1007/s11069-011-9834-4.

[145] R. H. Reichle, R. D. Koster, J. Dong, and A. A. Berg, "Global soil moisture from satellite observations, land surface models, and ground data: Implications for data assimilation," J. Hydrometeorol., vol. 5, no. 3, pp. 430-442, 2004, doi:10.1175/15257541(2004)005<0430:GSMFSO > 2.0.CO;2.

[146] R. H. Reichle, W. T. Crow, R. D. Koster, H. Sharif, and S. P. P. Mahanama, "Contribution of soil moisture retrievals to land data assimilation products," Geophys. Res. Lett., vol. 35, 2008, Art. no. L01404, doi:10.1029/2007GL031986.

[147] Reliefweb, South Africa Faces Severe Drought, 2015. [Online]. Available: http://reliefweb.int/report/south-africa/south-africa-faces-severedrought, Accessed on: 14 May 2016.
[148] Reliefweb,South African drought follows third-driest season in 80 years, 2015. [Online]. Available: http://reliefweb.int/report/south-africa/southafrican-drought-follows-third-driest-season-80-years, Accessed on: 4 June 2016.

[149] B. Renard, D. Kavetski, G. Kuczera, M. Thyer, and S. W. Franks, "Understanding predictive uncertainty in hydrologic modeling: The challenge of identifying input and structural errors," Water Resour. Res., vol. 46, no. 5, 2010, Art. no. W05521, doi:10.1029/2009WR008328.

[150] D. A. Robinson et al., "Soil moisture measurement for ecological and hydrological watershed-scale observatories: A review," Vadose Zone J., vol. 7, no. 1, pp. 358-389, 2008, doi:10.2136/vzj2007.0143.

[151] N. J. Rodriguez-Fernandez et al., "Soil moisture retrieval using neural networks: Application to SMOS," IEEE Trans. Geosci. Remote Sens., vol. 53, no. 11, pp. 5991-6007, 2015, doi:10.1109/TGRS.2015. 2430845 .

[152] K. Schamm et al., GPCC Full Data Daily Version 1.0 at 1.0 : Daily Land-Surface Precipitation from Rain-Gauges built on GTS-based and Historic Data, 2015, doi:10.5676/DWD_GPCC/FD_D_V1_100.

[153] S. Schneider, A. Jann, and T. Schellander-Gorgas, "Downscaling of seasonal soil moisture forecasts using satellite data," Hydrol. Earth Syst. Sci., vol. 18, no. 8, pp. 2899-2905, 2014, doi:10.5194/hess-18-2899-2014.

[154] K. Scipal, W. Wagner, M. Trommler, and K. Naumann, "The global soil moisture archive 1992-2000 from ERS scatterometer data: First results," in Proc. Geosci. Remote Sens. Symp., 2002, Toronto, ON, Canada, pp. 1399-1401.

[155] K. Scipal, M. Drusch, and W. Wagner, "Assimilation of a ERS scatterometer derived soil moisture index in the ECMWF numerical weather prediction system," Adv. Water Resour, vol. 31, no. 8, pp. 1101-1112, 2008, doi:10.1016/j.advwatres.2008.04.013.

[156] K. Scipal, T. Holmes, R. de Jeu, V. Naeimi, and W. Wagner, "A possible solution for the problem of estimating the error structure of global soil moisture data sets," Geophys. Res. Lett., vol. 35, pp. 24401-24404, Art. no. L24403, 2008, doi:10.1029/2008GL035599.

[157] S. I. Seneviratne, D. Lüthi, M. Litschi, and C. Schär, "Land-atmosphere coupling and climate change in Europe," Nature, vol. 443, pp. 205-209, 2006, doi:10.1038/nature05095.

[158] S. I. Seneviratne et al., "Investigating soil moisture-climate interactions in a changing climate: A review," Earth-Sci. Rev., vol. 99, no. 3, pp. 125161, 2010, doi:10.1016/j.earscirev.2010.02.004.

[159] J. Sheffield, E. F. Wood, and M. L. Roderick, "Little change in global drought over the past 60 years," Nature, vol. 491, pp. 435-438, 2012 , doi:10.1038/nature11575.

[160] P. K. Srivastava, D. Han, M. A. Rico-Ramirez, D. Al-Shrafany, and T. Islam, "Data fusion techniques for improving soilmoisture deficit usingSMOSsatellite andWRF-NOAHland surface model," Water Resour. Manage., vol. 27, pp. 5069-5087, 2013, doi:10.1007/s11269-013-04527.

[161] S. C. Steele-Dunne et al., "Feasibility of soil moisture estimation using passive distributed temperature sensing," Water Resour. Res., vol. 46, no. 3, 2010, doi:10.1029/2009WR008272.

[162] S. C. Steele-Dunne, J. Friesen, and N. van de Giesen, "Using diurnal variation in backscatter to detect vegetation water stress," IEEE Trans. Geosci. Remote Sens., vol. 50, no. 7, pp. 2618-2629, 2012, doi:10.1109/TGRS.2012.2194156.

[163] A. Stoffelen, "Toward the true near-surface wind speed: Error modeling and calibration using triple collocation," J. Geophys. Res., vol. 103, pp. 7755-7766, 1998, doi:10.1029/97JC03180.

[164] C.-H. Su, D. Ryu, A. W. Western, and W. Wagner, "De-noising of passive and active microwave satellite soil moisture time series," Geophys. Res. Lett., vol. 40, no. 14, pp. 3624-3630, 2013, doi:10.1002/grl.50695.

[165] C.-H. Su, D. Ryu, W. T. Crow, and A. W. Western, "Stand-alone error characterisation of microwave satellite soil moisture using a Fourier method," Remote Sens. Environ., vol. 154, pp. 115-126, 2014 doi:10.1016/j.rse.2014.

[166] C.-H. Su et al., "Evaluation of post-retrieval de-noising of active and passive microwave satellite soil moisture," Remote Sens. Environ., vol. 163, pp. 127-139, 2015, doi:10.1016/j.rse.2015.03.010.

[167] C. M. Taylor, R. A. de Jeu, F. Guichard, P. P. Harris, and W. A. Dorigo, "Afternoon rain more likely over drier soils," Nature, vol. 489, no. 7416, pp. 423-426, 2012, doi:10.1038/nature11377.

[168] E. Tebbs, F. Gerard, A. Petrie, and E. De Witte, "Emerging and potential future applications of satellite-based soil moisture products," in Satellite Soil Moisture Retrievals: Techniques \& Applications, G.P. Petropoulos, P. Srivastava, Y. Kerr Eds. Amsterdam, The Netherlands: Elsevier, pp. 379_ 400, 2016, ch. 19, doi:10.1016/B978-0-12-803388-3.00019-X. 
[169] M. Temimi et al., "A multi-temporal analysis of AMSR-E data for flood and discharge monitoring during the 2008 flood in Iowa," Hydrol. Process., vol. 25, no. 16, pp. 2623-2634, 2011, doi: 10.1002/hyp.8020.

[170] The World Bank, Populations at Risk of Disaster: A Resettlement Guide, Global Facility for Disaster Risk and Recovery, Washington DC, USA, 2011.

[171] F. Todisco, L. Brocca, L. Termite, and W. Wagner, "Use of satellite and modelled soil moisture data for predicting event soil loss at plot scale," Hydrol. Earth Syst. Sci., vol. 19, pp. 3845-3856, 2015, doi:10.5194/hess19-3845-2015.

[172] K. E. Trenberth, L. Smith, T. Qian, A. Dai, and J. Fasullo, "Estimates of the global water budget and its annual cycle using observational and model data," J. Hydrometeorol., vol. 8, pp. 758-769, 2007, doi:10.1175/JHM600.1.

[173] K. E. Trenberth and G. R. Asrar, "Challenges and opportunities in water cycle research: WCRP contributions," Surv. Geophys., vol. 35, no. 3, pp. 515-532, 2014, doi:10.1007/s10712-012-9214-y.

[174] S. E. Tuttle and G. D. Salvucci, "A new approach for validating satellite estimates of soil moisture using large-scale precipitation: Comparing AMSR-E products," Remote Sens. Environ., vol. 142, pp. 207-222, 2014, doi:10.1016/j.rse.2013.12.002.

[175] S. Tuttle and G. Salvucci, "Empirical evidence of contrasting soil moisture-precipitation feedbacks across the United States," Science, vol. 352, no. 6287, pp. 825-828, 2016, doi:10.1126/science .aaa7185.

[176] G. Vachaud, A. Passerat de Silans, P. Balabanis, and M. Vauclin, "Temporal stability of spatially measured soil water probability density function," Soil Sci. Soc. Amer. J., vol. 49, no. 4, pp. 822-828, 1985, doi:10.2136/sssaj1985.03615995004900040006x.

[177] B. Van den Hurk, F. Doblas-Reyes, G. Balsamo, R. D. Koster, S. I. Seneviratne, and H. Camargo, "Soil moisture effects on seasonal temperature and precipitation forecast scores in Europe," Climate Dyn., vol. 1/2, pp. 349-362, 2012, doi:10.1007/s00382-010-0956-2.

[178] T. Van Emmerik, S. C. Steele-Dunne, J. Judge, and N. van de Giesen, "Impact of diurnal variation in vegetation water content on radar backscatter from maize during water stress," IEEE Trans. Geosci. Remote Sens., vol. 53, no. 7, 2015, pp. 3855-3869, Jul. 2015, doi:10.1109/TGRS.2014.2386142.

[179] A. F. Van Loon et al., "Drought in the Anthropocene," Nature Geosci., vol. 9, no. 2, pp. 89-91, 2016, doi:10.1038/ngeo2646.

[180] K. Vanderlinden et al., "Temporal stability of soil water contents: a review of data and analyses," Vadose Zone J., vol. 11, no. 4, 2012, doi:10.2136/vzj2011.0178.

[181] H. Vereecken et al., "On the spatiotemporal dynamics of soil moisture at the field scale," J. Hydrol., vol. 516, pp. 76-96, 2014, doi:10.1016/j.jhydrol.2013.11.061

[182] H. Vereecken et al., "Modelling soil processes: Key challenges and new perspectives," Vadose Zone J., vol. 15, 2016, doi:10.2136/vzj2015.09.0131.

[183] W. W. Verstraeten et al., "Remotely sensed soil moisture integration in an ecosystem carbon flux model. The spatial implication," Climate Change, vol. 103, no. 1/2, pp. 117-136, 2010, doi:10.1007/s10584-010-9920-8.

[184] P. Viterbo and A. Beljaars, "An improved land surface parameterization scheme in the ECMWF model and its validation," J. Climate, no. 8, pp. 2716-2748, 1995, doi:10.1175/15200442(1995)008<2716:AILSPS $>2.0$. CO;2.

[185] M. Vreugdenhil, W. A. Dorigo, W. Wagner, R. A. M. Jeu, S. Hahn, and M. J. E. Marle, "Analyzing the vegetation parameterization in the TU-Wien ASCAT soil moisture retrieval," IEEE Trans. Geosci. Remote Sens., vol. 54, no. 6, pp. 3513-3531, Jun. 2016 , doi:10.1109/TGRS.2016.2519842.

[186] M. Vreugdenhil et al., "Assessing vegetation dynamics over mainland Australia with metop ASCAT," IEEE J. Sel. Topics Appl. Earth Observ., to be published, doi:10.1109/JSTARS.2016.2618838.

[187] F. Vuolo and C. Atzberger, "Exploiting the classification performance of support vector machines with multi-temporal moderate-resolution imaging spectroradiometer (MODIS) data in areas of agreement and disagreement of existing land cover products," Remote Sens., vol. 4, pp. 3143-3167, 2012, doi: 10.3390/rs4103143.

[188] W. Wagner et al., "Operational readiness of microwave remote sensing of soil moisture for hydrologic applications," Nord. Hydrol., vol. 38, pp. 1-20, 2007, doi:10.2166/nh.2007.029.

[189] W. Wagner, G. Lemoine, M. Borgeaud, and H. Rott, "A study of vegetation cover effects on ERS scatterometer data," IEEE Trans. Geosci. Remote Sens., vol. 37, no. 2, pp. 938-948, Mar. 1999, doi:10.1109/36.752212.
[190] W. Wagner, G. Lemoine, and H. Rott, "A method for estimating soil moisture from ERS scatterometer and soil data," Remote Sens. Environ., vol. 70, pp. 191-207, 1999, doi:10.1016/S0034-4257(99)00036-X.

[191] W. Wagner et al., "Temporal stability of soil moisture and radar backscatter observed by the advanced synthetic aperture radar (ASAR)," Sensors, vol. 8, pp. 1174-1197, 2008, doi:10.3390/s80201174.

[192] W. Wagner et al., "Fusion of active and passive microwave observations to create an Essential Climate Variable data record on soil moisture," ISPRS Ann Photogrammetry, Remote Sens. Spatial Inf. Sci., vol. 25, pp. 315-321, 2012.

[193] W. Wagner et al., "The ASCAT soil moisture product: A review of its specifications, validation results, and emerging applications," Meteorol. Z., vol. 22, no. 1, pp. 5-33, 2013, doi:10.1127/0941-2948/2013/0399.

[194] W. Wagner et al., "Operations, challenges and prospects of satellite based surface soil moisture services," in Remote Sensing of Land Surface Turbulent Fluxes and Soil Moisture Content: State of the ART, G. P. Petropoulos Ed. London, U.K.: CRC Press, 2013, ch. 20, pp. 463-488, , doi:10.1201/b15610-25.

[195] W. Wagner et al., "Clarifications on the "Comparison between SMOS, VUA, ASCAT, and ECMWF soil moisture products over four watersheds in U.S.," IEEE Trans. Geosci. Remote Sens., vol. 52, no. 3, pp. 19011906, Mar. 2014, doi:10.1109/TGRS.2013.2282172.

[196] B. Wake, "Flooding costs," Nature Climate Change, vol. 3, p. 778, 2013, doi:10.1038/nclimate1997.

[197] N. Wanders, D. Karssenberg, A. D. Roo, S. M. De Jong, and M. F. P. Bierkens, "The suitability of remotely sensed soil moisture for improving operational flood forecasting," Hydrol. Earth Syst. Sci., vol. 18, no. 6, pp. 2343-2357, 2014, doi:10.5194/hess-18-2343-2014.

[198] N. Wanders, M. Pan, and E. F. Wood, "Correction of real-time satellite precipitation with multi-sensor satellite observations of land surface variables," Remote Sens. Environ., vol. 160, pp. 206-221, 2015, doi:10.1016/j.rse.2015.01.016.

[199] B. Wardlow, T. Anderson, C. Tadesse, W. Hain, and M. Rodell, "Remote sensing of drought: Emergence of a satellite-based monitoring toolkit for the United States," in Remote Sensing of Water Resources, Disasters, and Urban Studies, Prasad S. Thenkabail Ed. Boca Raton, FL, USA: CRC Press, pp. 367-398, 2016.ch. 15.

[200] K. Whan et al., "Impact of soil moisture on extreme maximum temperatures in Europe," Weather Climate Extremes, vol. 9, pp. 57-67, 2015. doi:10.1016/j.wace.2015.05.001.

[201] D. A. Wilhite, "Drought as a natural hazard: Concepts and definitions," in Drought: A Global Assessment, Donald A. Wilhite Ed. London, U.K.: Routledge Publishers, , pp. 3-18, 2000, ch. 1.

[202] D. A. Wilhite and M. H. Glantz, "Understanding the drought phenomenon: The role of definitions," Water Int., vol. 10, pp. 111-120, 1985, doi:10.1080/02508068508686328.

[203] D. A. Woolhiser, R. E. Smith, and J. V. Giraldez, "Effects of spatial variability of saturated hydraulic conductivity on Hortonian overland flow," Water Resour. Res., vol. 32, no. 3, pp. 671-678, 1996, doi:10.1029/95WR03108.

[204] M. Zribi et al., "Relationship between soil moisture and vegetation in the Kairouan plain region of Tunisia using low spatial resolution satellite data," Water Resour. Res., vol. 46, no. 6, 2010, doi:10.1029/2009WR008196.

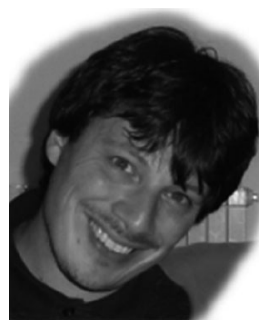

Luca Brocca was born in Genoa, Italy, in 1978. He received the M.S. degree in environmental engineering and the Ph.D. degree in civil engineering, both with excellence, from the University of Perugia, Perugia, Italy, in 2003 and 2008, respectively.

Since 2009, he is a Researcher at the Research Institute of geo-Hydrological Protection, National Research Council, Perugia, Italy. He has been the author and coauthor of 83 journal papers and 76 papers in conference proceedings. He is involved in teaching and tutorial activity in the University of Perugia. His research interest focuses on the development innovative methods for exploiting satellite observations (soil moisture, rainfall, discharge) in hydrological applications (flood, landslide, drought, etc.).

Dr. Brocca serves as a Reviewer for more than 35 international journals and as an Associate Editor of Geoderma and Hydrology journals. He actively participates to several research project in the frame of Italian and European programs (LIFE+, HORIZON2020), and funded by Space Agencies (ESA, EUMETSAT), in collaboration with Italian and international institutions. He is the Italian National Correspondent of the Euromediterranean network of Experimental and Representative Basins and he is the member of IAHS, SII, GII, iEMSs, and EGU. 


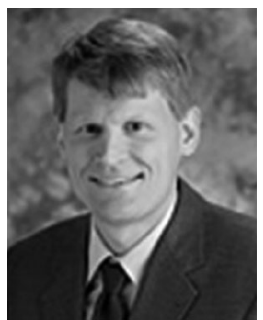

Wade T. Crow received the Ph.D. degree in 2001 from Princeton University, Princeton, NJ, USA.

$\mathrm{He}$ is currently a Research Physical Scientist and Project Lead Scientist at the USDA ARS Hydrology and Remote Sensing Laboratory, Beltsville, MD, USA. His research focuses on the development of hydrologic and agricultural applications for remote sensing data and the development of appropriate data assimilation approaches to facilitate this goal, with a special emphasis on techniques that fuse information from various disparate remote sensing sources. This work has led to extensive collaboration with operational USDA agencies involved in drought monitoring missions. He has served (or currently serves) on the science teams for the NASA GPM, Hydros, SMAP, and AirMOSS missions, and was an Editor of the American Meteorological Society.s Journal of Hydrometeorology.

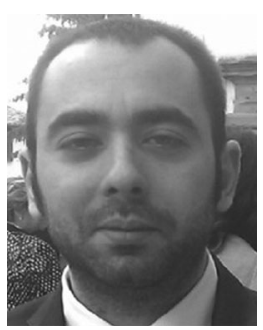

Luca Ciabatta was born in Perugia, Italy, in 1985. He received the M.S. degree in geological sciences and technologies with excellence, from the University of Perugia, Perugia, Italy, in May 2012.

Since February 2013, he is a Research Fellow at the Research Institute for Geo-Hydrological Protection, National Research Council, Perugia, Italy. His research interest focuses on the use of satellite data for hydrological applications and geo-hydrological risk assessment.

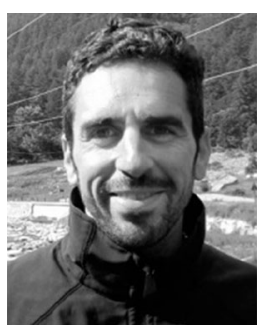

Christian Massari was born in Cascia, Perugia, Italy, in 1981. He received the M.S. degree in environmental engineering and the Ph.D. degree in hydraulic engineering, both with excellence, from the University of Perugia, Perugia, Italy, in 2008 and 2012, respectively.

In support of the Ph.D. degree, he received fellowships to carry out research in the Department of Hydrology and Water Resources, University of Arizona, Tucson, AZ, USA, where he has worked in the field of hydraulic groundwater and hydraulic tomographic techniques. From November 2011 to February 2013, he has been a Research Fellow in the "Dipartimento di Ingegneria Civile ed Ambientale," University of Perugia, where he has worked on the development of data fusion techniques for the diagnosis of pressurized pipe systems. Since February 2013, he has been a Researcher in the Research Institute for Geo-Hydrological Protection, National Research Council, Perugia, Italy, where he has been working in the field of hydrology and remote sensing. Since Spring 2016, he has been a Visiting Scientist in the United States Department of Agriculture, Beltsiville, MD, USA, where he has worked in the field of satellite precipitation error estimation. $\mathrm{He}$ is the author and coauthor of 31 journal referred papers and 21 papers in peer-reviewed conference proceedings/book chapters and national journals. He has held more than 20 presentations at conferences and workshops and serves as a frequent reviewer for several international journals. He is involved in the validation activities of 1) the Global Precipitation Measurement (GPM) mission products; 2) the European Space Agency Climate Change Initiative soil moisture product; 3) the rainfall and soil moisture products of the H-SAF project of EUMETSAT; and 4) Soil Moisture Active and Passive product of NASA. His research interests include data fusion and data assimilation of hydrological variables (e.g., soil moisture and rainfall), hydro-validation of satellite soil moisture and rainfall observations, filtering of satellite soil moisture, flooding risk analysis, and flood frequency assessment.

Dr. Massari is a member of SII, GII, and EGU.

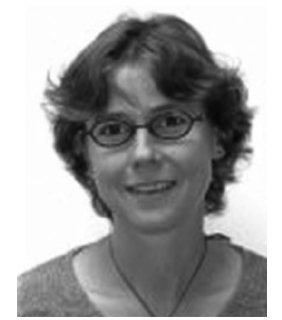

Patricia De Rosnay received the Ph.D. degree.

She is a senior scientist at the European Centre for Medium-Range Weather Forecasts (ECMWF), Shinfield, U.K., where she is seconded from the French Centre National de la Recherche Scientifique. She is responsible of the ECMWF Coupled Assimilation Team. From 1994 to 2002, she worked on land surface modelling and climate modelling at Laboratoire de Météorologie Dynamique/Institut PierreSimon Laplace, Paris, and from 2002 to 2007, on land surface modeling and remote sensing at Centre d'Etudes Spatiales de la Biosphère, Toulouse, France. Her current research focuses on land surface observations monitoring (SMOS, ASCAT, and conventional surface observations), Land Data Assimilation System developments and coupled data assimilation for Numerical Weather Prediction. She implemented a new Optimal Interpolation snow analysis and an Extended Kalman Filter soil moisture analysis in the ECMWF Integrated Forecasting System.

Dr. De Rosnay is a member of the HarmoSnow COST action, EUMESAT H-SAF project Team and the NASA Application Working Group of the Soil moisture Active Passive mission. She is also a member of the Short-Range Numerical Weather Prediction Programme surface expert team, as well as the WMO SnowWatch Team of the Global Cryosphere Watch programme.

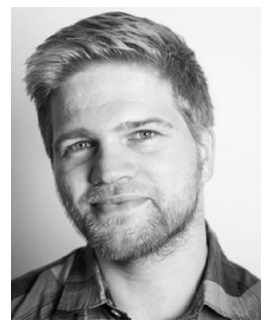

Markus Enenkel is a Postdoctoral Research Scientist with a background in resource/disaster management and earth observation. Having worked with different decision-makers (e.g., Doctors without Borders, International Red Cross, UN) and research organizations, he aims at closing knowledge gaps via research-based decision-support. His previous work included the development of a tailored drought and food security monitor for Doctors without Borders, a mobile app for rapid food security assessment, and an operational multisensor soil moisture dataset. His current research interests focus on the integration of satellite-derived soil moisture into the weather risk index development process, the analysis of climatic shifts related to index design, and a study on the added-value of various complementary satellite-derived datasets for weather index insurance in sub-Saharan Africa. Markus supports the capacity building/knowledge transfer activities between the IRI, smallholder farmers, stakeholders, as well as other research groups. Finally, he acts as liaison between the IRI and SOS Children's Villages International.

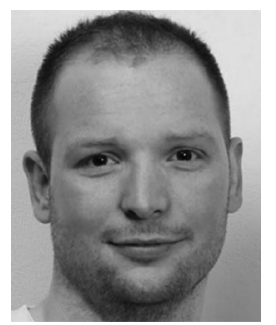

Sebastian Hahn was born in Vienna, Austria, in 1985. He received the B.Sc. degree in geodesy and geomatic engineering and the M.Sc. degree in geodesy and geophysics from Vienna University of Technology, Vienna, in 2009 and 2011, respectively. He is currently working toward the Ph.D. degree with the Vienna University of Technology.

Since April 2010, he has been a Project Assistan with the Research Group Remote Sensing, Department of Geodesy and Geoinformation, Vienna University of Technology. He is currently one of the key developers for the software package WARP (Soil Water Retrieval Package) which represents the implementation of the TU Wien soil moisture retrieval algorithm. As a developer, he is focused on software design, multiprocessing, model calibration, and algorithmic improvements, which is in light of his Ph.D. studies. His main research interests include remote sensing over land using active microwave instruments, active soil moisture retrieval algorithms, software development, and validation of soil moisture products.

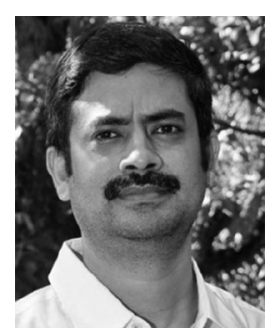

Giriraj Amarnath received the M.Sc. degree in botany from the Madras Christian College (Chennai), India, in 1999, and the Ph.D. degree from Bharathidasan University, Tiruchirappalli, India, in 2004.

In 2011, he was with the International Water Management Institute (IWMI) as a Senior Researcher in Remote Sensing and Water Resources. He is currently a Sub Theme Leader: Water-related Disaster Risk Management and conducting his research on floods and drought monitoring and risk assessment and weather index insurance for agricultural development. His research interests include image analysis, data fusion in remote sensing and application products. 


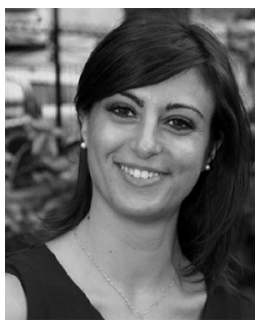

Stefania Camici was born in L'Aquila, in 1983. She received the the Master's and Ph.D. degrees in environmental engineering from the University of Perugia, Perugia, Italy, in 2008 and 2016, respectively.

Since 2008 she has working at Research Institute of Geo-Hydrological Protection (IRPI), National Research Council (CNR) in Perugia in the field of flooding risk assessment also in a context of climate change. Since September 2012, she has been a Researcher at CNR-IRPI and her work has been focused on the analysis of climate change impact on flood frequency by using different climate models and statistical downscaling. From April to June 2015 she has been Visiting Researcher at Institute for Atmospheric and Climate Science, Swiss Federal Institute of Technology, Zurich, Switzerland, within the group of Prof. Seneviratne. In these research areas, she has is co-author of 28 original contributions with 11 ISI journal articles and 17 in proceedings of national and international conferences. She has participated in several research projects in collaboration with Italian and international institutions.

Dr. Camici is a member of Italian Hydrology Society (SII), Italian Group of Hydraulics (GII), and European Geophysical Union (EGU).

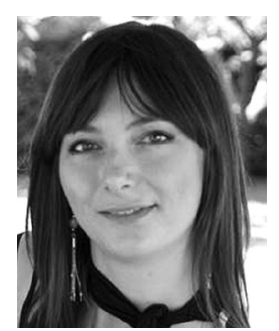

Angelica Tarpanelli was born in Assisi, Italy, in 1981. She received the Master.s and Ph.D. degrees in environmental engineering from the University of Perugia, Perugia, Italy, 2006 and 2014, respectively.

In September 2006, she received a scholarship and a Research Fellowship to carry research in flooding risk assessment at the Research Institute of GeoHydrological Protection (IRPI), National Research Council (CNR) of Perugia, Italy. Since 2012, she is a Researcher at CNR-IRPI. Her research interests focus on the use of remote sensing for hydrological and hydraulic applications, especially on the river discharge estimation. She has been author and co-author of 14 journal referred papers and 28 papers in peer-reviewed conference proceedings/book chapters. She has participated to several research projects in the frame of Italian and European programs and in collaboration with Italian and international institutions.

Dr. Tarpanelli is a member of the Italian Hydrological Society (IHS) and Hydraulic Group (GII), and the European Geophysical Union (EGU).

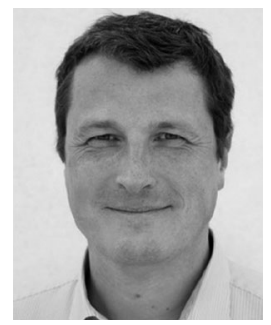

Wolfgang Wagner (M'98-SM'07) was born in Austria in 1969. He received the Dipl.-Ing. degree in physics and the Dr.techn. degree in remote sensing from the Vienna University of Technology (TU Wien), Wien, Austria, in 1995 and 1999, respectively.

In support of his Master's and $\mathrm{PhD}$ studies, he received fellowships to carry out research at the University of Bern, Atmospheric Environment Service Canada, NASA, ESA, and the EC Joint Research Centre. From 1999 to 2001, he was with DLR. In 2001 he was appointed as a Professor of remote sensing at TU Wien. Since 2012, he has been the Head of the Department of Geodesy and Geoinformation, TU Wien. He is the co-founder and Head of Science of the EODC Earth Observation Data Centre. His main research interest is to gain physical understanding of the mechanisms driving the interaction of electromagnetic waves with the land surface. Based on this understanding, he has developed models for retrieving soil moisture, biomass, and other land surface variables from scatterometer, SAR, and full-waveform lidar observations.

Dr. Wagner is a member of the EUMETSAT/ESA Science Advisory Group for METOP-SG SCA, and since 2016, the Chair of the GCOS/WCRP Terrestrial Observation Panel for Climate. From 2008 to 2012, he was the ISPRS Commission VII President and from 2009 to 2011 the Editor-in-Chief of the Open Access Journal "Remote Sensing". He received the ISPRS Frederick J. Doyle Award for his scientific contributions in active remote sensing. 